\title{
Recent Advances in Polymer Nanomaterials for Drug Delivery of Adjuvants in Colorectal Cancer Treatment: A Scientific-Technological Analysis and Review
}

\author{
Marlon Osorio $^{1}$, Estefanía Martinez ${ }^{1}$, Tonny Naranjo ${ }^{2,3}$ and Cristina Castro ${ }^{1, *(\mathbb{D}}$ \\ 1 School of Engineering, Universidad Pontificia Bolivariana, Circular 1 \# 70-01, Medellín 050031, Colombia; \\ marlonandres.osorio@upb.edu.co (M.O.); estefania.martinezc@upb.edu.co (E.M.) \\ 2 School of Health Sciences, Universidad Pontificia Bolivariana, Calle 78 B \# 72 A-109, Medellín 050034, \\ Colombia; tonny.naranjo@upb.edu.co \\ 3 Medical and Experimental Mycology Group, Corporación para Investigaciones Biológicas, Carrera 72 A \# 78 \\ B-141, Medellín 050034, Colombia \\ * Correspondence: cristina.castro@upb.edu.co; Tel.: +57-448-8388 (ext. 13288)
}

Academic Editors: Carlos A. García-González, Pasquale Del Gaudio and Ricardo Starbird Received: 19 April 2020; Accepted: 1 May 2020; Published: 12 May 2020

check for updates

\begin{abstract}
Colorectal cancer (CRC) is the type with the second highest morbidity. Recently, a great number of bioactive compounds and encapsulation techniques have been developed. Thus, this paper aims to review the drug delivery strategies for chemotherapy adjuvant treatments for CRC, including an initial scientific-technological analysis of the papers and patents related to cancer, CRC, and adjuvant treatments. For 2018, a total of 167,366 cancer-related papers and 306,240 patents were found. Adjuvant treatments represented $39.3 \%$ of the total CRC patents, indicating the importance of adjuvants in the prognosis of patients. Chemotherapy adjuvants can be divided into two groups, natural and synthetic (5-fluorouracil and derivatives). Both groups can be encapsulated using polymers. Polymer-based drug delivery systems can be classified according to polymer nature. From those, anionic polymers have garnered the most attention, because they are $\mathrm{pH}$ responsive. The use of polymers tailors the desorption profile, improving drug bioavailability and enhancing the local treatment of CRC via oral administration. Finally, it can be concluded that antioxidants are emerging compounds that can complement today's chemotherapy treatments. In the long term, encapsulated antioxidants will replace synthetic drugs and will play an important role in curing CRC.
\end{abstract}

Keywords: colorectal cancer; antioxidants; 5-fluorouracil; polymer nanomaterials; nanocapsules; chemotherapy

\section{Introduction}

Every sixth death in the world is due to cancer, making it the second leading cause of death [1,2], and despite survival rates increasing, according to the Institute for Health Metrics and Evaluation of the University of Seattle, more than a million people died because of cancer globally in 2017 [3]. In 2016, more than 8.15 million people suffered from breast cancer, which was the type with the most morbidity, followed by colorectal cancer (CRC) and prostate cancer with 6.32 million and 5.7 million cases, respectively [1]. Of these three cancer types, CRC represents the highest number of deaths [3]. Several factors increase the risk of cancer; however, advancing age is the most important for cancer overall, and for CRC, specifically, a diet rich in meat cooked at high temperatures is associated with an increased risk of CRC [4].

Moreover, moderate-to-heavy alcohol consumption is associated with a 1.2- to 1.5-fold increased risk of CRC [5]. Others factors include African American ethnicity, male sex, inflammatory bowel 
disease, obesity, a sedentary lifestyle, red meat and processed meat intake, tobacco use, a history of abdominal radiation, acromegaly, renal transplant with use of immunosuppressive medications, diabetes mellitus and insulin resistance, androgen deprivation therapy, cholecystectomy, coronary artery disease, and ureterocolic anastomosis [6].

All of the above have led to a huge interest in cancer research. Today, cancer research is focused on identifying the causes and developing strategies for the prevention, diagnosis, treatment, and cure of cancer [7]. Cancer is one of the most investigated subjects; for instance, the proportion of cancer-related entries in PubMed rose from 6\% in 1950 to 16\% in 2016 [8], being even higher than for other diseases such as various infections (malaria, AIDS, tuberculosis, among others) and diabetes [8].

Accordingly, there is huge scientific research interest in treating and curing CRC, and several strategies have arisen to improve the therapeutic effects and reduce the side effects of actual chemotherapy for CRC treatment. Most of them include polymer drug delivery systems. Thus, this paper aims to review polymer drug delivery systems for adjuvant treatments for CRC, including an initial scientific-technological analysis of the papers and patents related to cancer, CRC, and adjuvant treatments using polymer approaches. The novelty of this paper lies in its broad overview of polymer families and the interaction of them with adjuvants. Moreover, it is explained how the behavior of those emerging drug delivery strategies is related to the superficial charge and chemical groups of the used polymers, information that, to the knowledge of the authors, is not reviewed in the literature for CRC.

\section{Scientific-Technological Analysis}

In Scopus, the total of cancer-related papers in 2018 was 2,857,590 (see Figure 1a), and CRC-related papers numbered 167,366 (see Figure 1b); both subjects presented an exponential rise from 1970. The first documents indexed in Scopus related to CRC were report cases of medical interventions; for instance, Mr. Luke (1860) reported the surgery of an intestinal obstruction resulting from CRC [9]. Similarly, Dunphy (1947) reported four cases of CRC and included a gross pathological evaluation of the tumors [10].

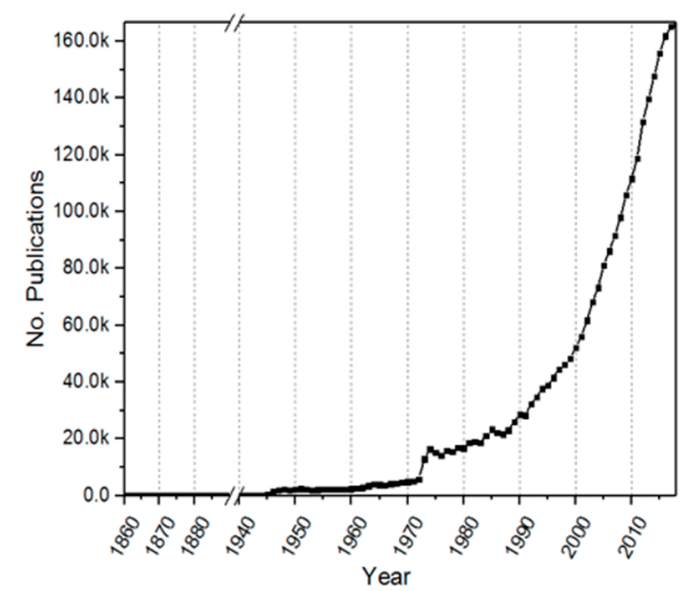

(a)

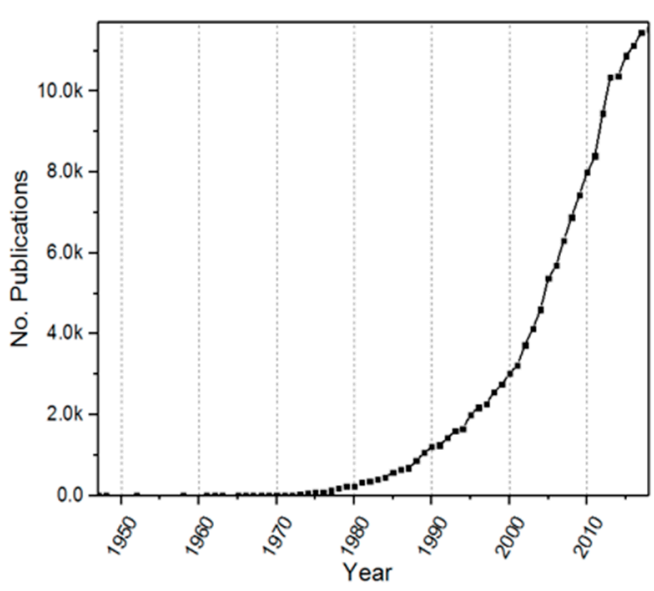

(b)

Figure 1. Number of publications of cancer in Scopus; (a) total number of cancer-related publications from 1860 to 2018 using the search string "TITLE-ABS-KEY (cancer)"; (b) total number of colorectal cancer-related publications from 1947 to 2018 using the search string "TITLE-ABS-KEY (colorectal and cancer)".

In 1970, the first paper that reported the use of adjuvants was published by Adams et al. (1970), in which they compared the use of intralymphatic 5-fluorouracil (5-FU) and radioactive gold as adjuvants to surgical operations for colorectal carcinoma [11]. The next year, another two papers were 
published, and today, more than 550 papers have been published on this matter per year (Scopus, search string "TITLE-ABS-KEY (colorectal and cancer and adjuvants)"), representing more than 7\% (about 11,700 research papers) of the overall CRC research.

Patents related to cancer represented around 2,356,397 entries from 1898 to 2018. The number of patents related to CRC is about 306,240 . The pattern of the number of patents per year is presented in Figure 2. It was interesting to find that that the number of patents related to cancer is lower than the number of scientific papers; this behavior can be related to the number of documents of clinical study cases that count for the papers.

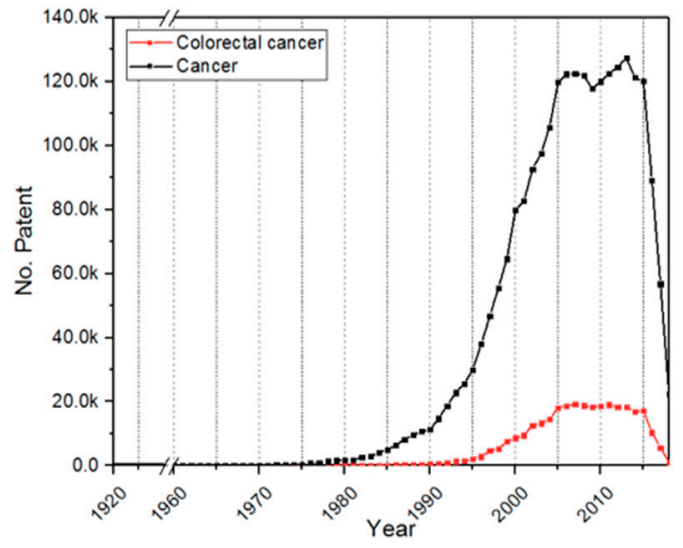

(a)

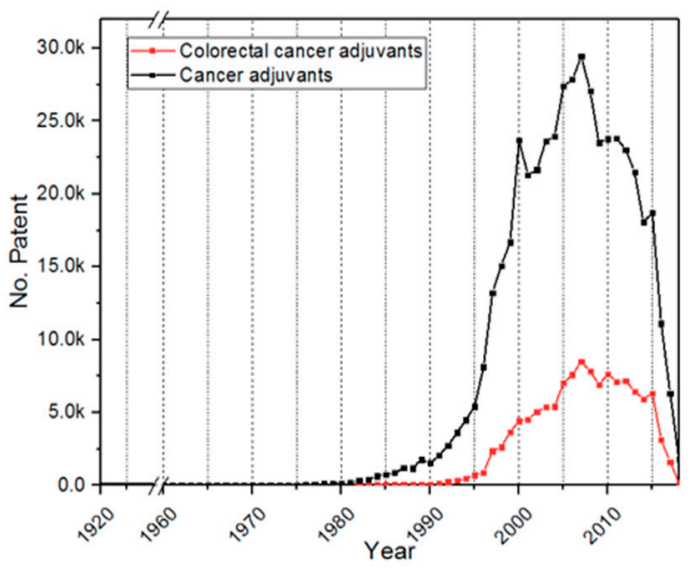

(b)

Figure 2. Number of patents per year in (a) cancer and colorectal cancer (CRC) (data found in AcclaimIP) - the words "cancer" and "colorectal cancer" were examined in the title, abstract and claims, separately; (b) cancer adjuvants and colorectal cancer adjuvants (data found in AcclaimIP)—the words "cancer adjuvant" and "colorectal cancer adjuvant" were searched for in the title, abstract and claims, separately.

Regarding adjuvant therapies, it was found that adjuvants represent $20.0 \%$ of the overall cancer patents, and for CRC, adjuvants represent $39.3 \%$. Thus, the number of patents related to adjuvants is proportionally higher for CRC (approximately two-fold) than for overall cancers, which can be explained by the motivation of scientists to cure the most deadly cancer type.

By comparing Figures 1 and 2, it can be seen that adjuvants are more likely to be patented than to be scientifically published ( $12.6 \mathrm{~K}$ vs. $478.9 \mathrm{~K})$ because scientists and companies prefer to protect their intellectual property that can be economically exploited. For instance, the global adjuvant market size was valued at USD 308.99 million in 2016 and is anticipated to grow with a compound annual growth rate (CAGR) of $10.6 \%$ [12]. Furthermore, it can be observed that while scientific papers grew rapidly, the number of patents grew until 2010 and then dropped. This behavior can be attributed to the recent difficulty of patenting because applicants' claims should be new and clearly different to previous work [13], which is vast in cancer research, meaning that only $50 \%$ of patent applications are adjudicated. This is also discouraging new applications, since authors and companies do not see an attractive cost-benefit ratio for the patenting process [13].

By analyzing the keywords in the latest 2000 papers in Scopus and the title phrases in 1000 patents in the Derwent software (Clarivate Analytics, PA, USA) and then grouping the main subjects (see Figure 3), it was found that adjuvants are the second group for cancer and CRC, with $28.5 \%$ and $23.0 \%$ of entries, respectively, showing the importance of adjuvant therapy for improving the success of cancer treatments. Emerging strategies such as immunotherapy and biomarkers for treating and classifying cancer were also found.

Regarding the group of adjuvants, it was found that the terms "drug" and "chemotherapy" are more important for CRC than for cancer overall (see Table 1), again exposing the importance of drug 
delivery strategies for CRC. The drugs with more studies in recent papers (organized per decreasing number of entries) for CRC treatment are 5-fluoraucil, bevacizumab, capecitabine, metformin, aspirin, and irinotecan. Aspirin and metformin drew attention because they are drugs that are used for other purposes. For instance, aspirin and acetyl-salicylates, are used for treating fever, inflammation and pain [14]; however, Garcia et al. (2012) concluded that daily aspirin use at any dose was associated with a $21 \%$ lower risk of all-cancer death [15], and Chang et al. (2009) reported that aspirin reduces the risk of colorectal neoplasia in randomized trials and inhibits tumor growth and metastases in animal models, especially in tumors that overexpress cyclooxygenase-2, whereas aspirin can reduce that expression [16].

Table 1. Comparison of keyword groups in scientific papers for cancer adjuvants and colorectal cancer adjuvants. Two thousand papers were extracted from Scopus and examined in their keywords and the documents up to 31/12/2018; the keywords were grouped using VantagePoint.

\begin{tabular}{ccc}
\hline \multirow{2}{*}{ Keyword Groups } & \multicolumn{2}{c}{ Percentage } \\
\cline { 2 - 3 } & Cancer Adjuvants & Colorectal Cancer Adjuvants \\
\hline Chemotherapy & 41.2 & 45.3 \\
Others adjuvant therapies & 23.8 & 13.9 \\
Drugs & 10.4 & 28.0 \\
Radiotherapy & 19.9 & 9.2 \\
Others & 4.8 & 3.6 \\
\hline
\end{tabular}

By analyzing the patents, it was found that the title phrases were more difficult to group and that the topics, in general, were more disperse (see Figure $3 \mathrm{c}, \mathrm{d}$ ); however, adjuvants and pharmaceutical compositions represent more than the $15 \%$ of the entries, coming in second place after cancer types, which includes the entries of all cancer names. Likewise, the drugs grouped in pharmaceutical composition for CRC are more diverse, but include indazoles derivatives, heteroaryl derivatives, heterocyclic compounds, quinoline compounds, and tumorigenic inhibitors, among others. These compounds are anticancer agents that have shown antiproliferative activity against cancer cells $[17,18]$.

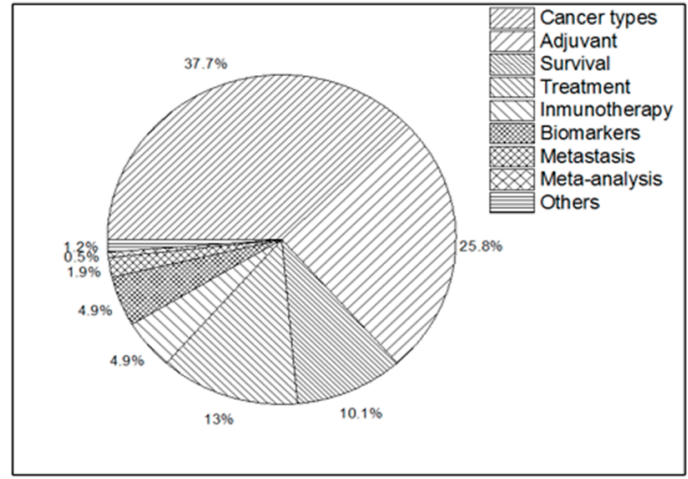

(a)

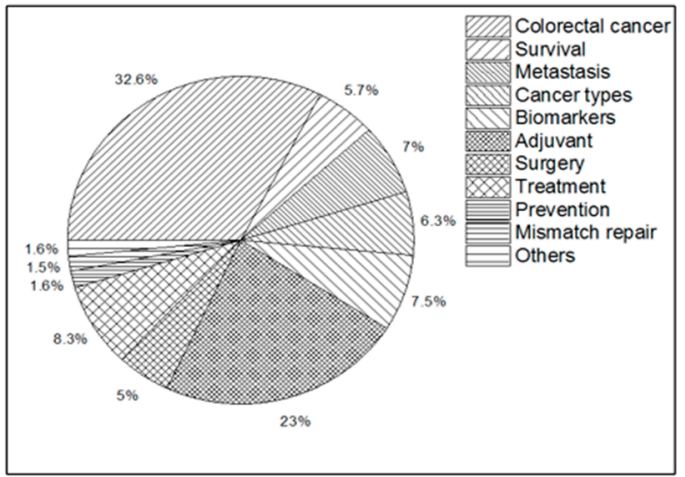

(b)

Figure 3. Cont. 


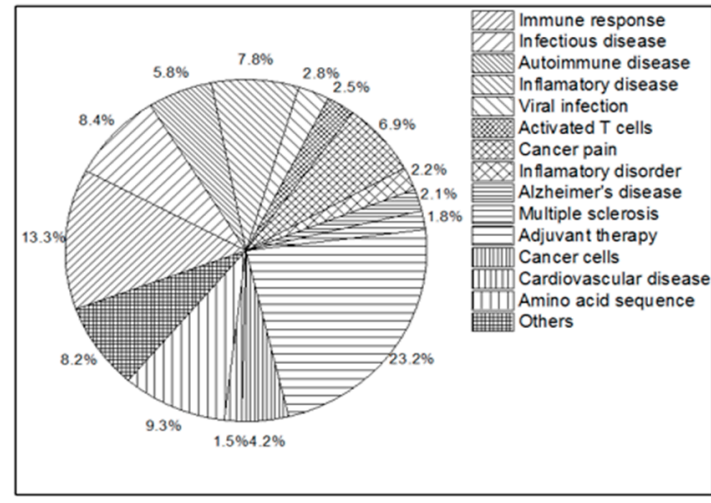

(c)

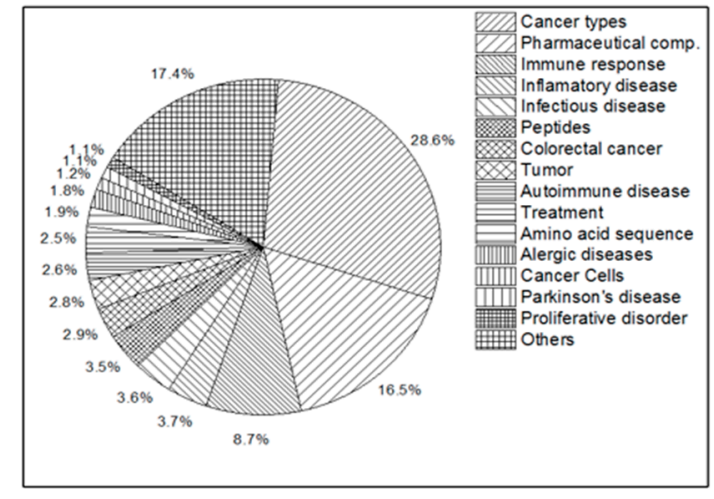

(d)

Figure 3. Keyword and title phrase groups in the latest papers and patents up to 31/12/2018; (a) grouped keywords of cancer adjuvants in scientific papers; (b) grouped keywords of colorectal cancer adjuvants in scientific papers; (c) grouped title phrases of cancer adjuvants in patents; (d) grouped title phrases of colorectal cancer adjuvants in patents. Authors' keywords were extracted from 2000 scientific papers in Scopus and analyzed using VantagePoint. Title patent phrases were extracted from 1000 patents of Derwent and analyzed using VantagePoint.

\section{Cancer}

According to the World Health Organization, "cancer is a generic term for a large group of diseases characterized by the growth of abnormal cells beyond their usual boundaries that can then invade adjoining parts of the body and/or spread to other organs" [19]. Cancer involves carcinogenesis, which means cancer development; more accuracy, carcinogenesis was first defined by Hecker in 1976 as the "generation of neoplasia" [20]. Neoplasia is an abnormal growth not coordinated with the surrounding tissue [21].

Cancer is initiated via carcinogens in the environment that induce mutations in critical genes, and these mutations direct the cell in which they occur, as well as all of its progeny cells, to grow abnormally. The result of this abnormal growth appears years later as a tumor [21].

Cancer has been traditionally classified in three ways: by the type of tissue in which cancer originates (histological type), by the primary body site, and by the staging (see Figure 4) $[19,21]$.

Histologically, cancer is classified as carcinoma, sarcoma, myeloma, leukemia, and lymphoma [22,23]. Carcinoma refers to a malignant neoplasm of epithelial origin, skin, and tissues that line or cover internal organs. There are two subtypes, adenocarcinoma, which develops in an organ or gland, and squamous cell carcinoma, which originates in the squamous epithelium [23].

Sarcoma refers to cancer that originates in supportive and connective tissues such as the bones, tendons, cartilage, muscle, and fat [22]. Myeloma is cancer that originates in the plasma cells of the bone marrow. Leukemias are also presented in the bone marrow, but this cancer type is associated with the overproduction of immature white blood cells. Leukemia also affects red blood cells and can cause poor blood clotting and fatigue due to anemia [23]. 


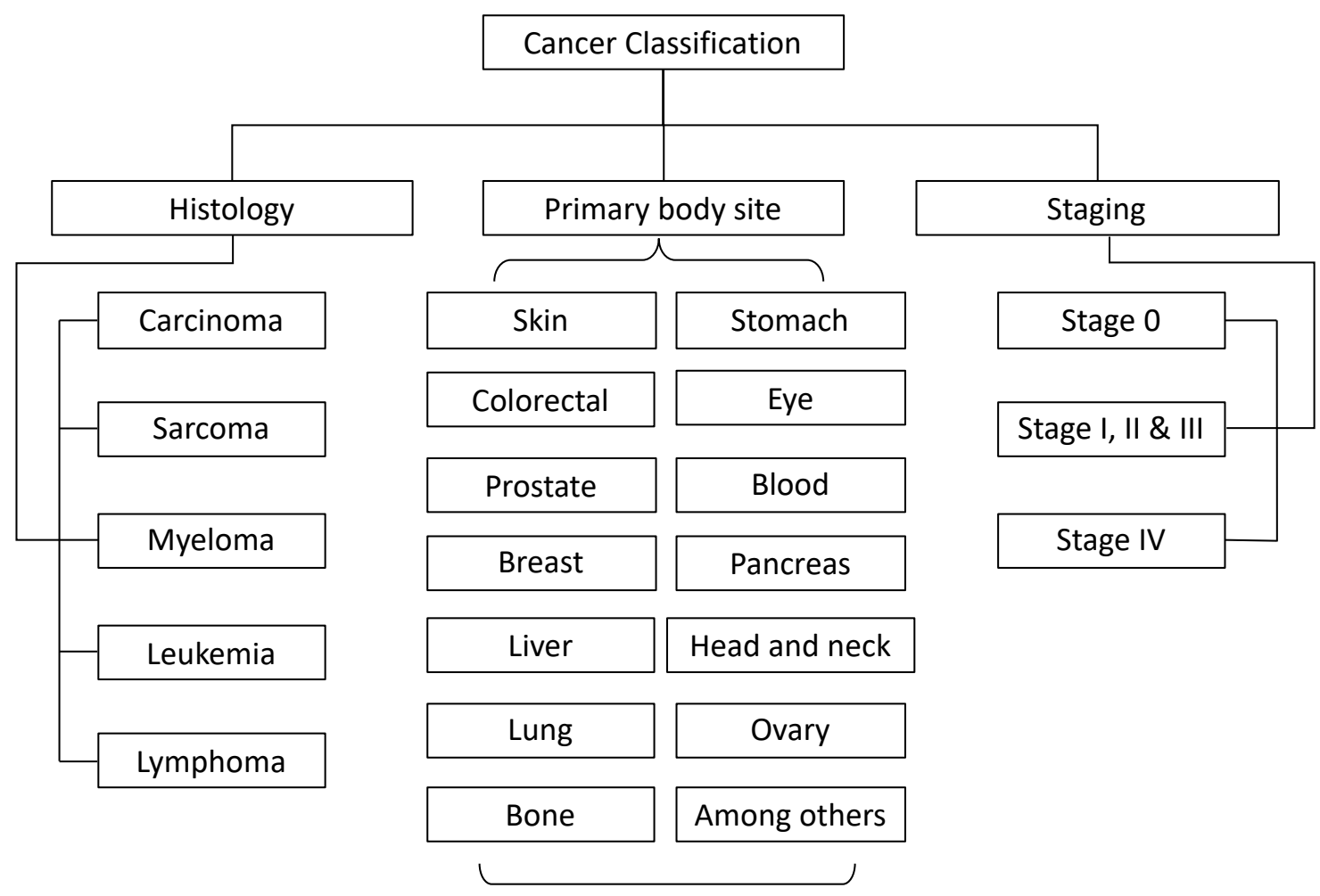

Figure 4. Traditionally cancer classification, histology, primary body site and staging.

Lymphomas develop in the glands or nodes of the lymphatic system-a network of vessels, nodes, and organs (specifically the spleen, tonsils, and thymus) that purify bodily fluids and produce infection-fighting white blood cells, or lymphocytes [22,23].

The body site classification is more familiar to patients, and it refers to the anatomical site at which the cancer appears, for instance, the brain, colorectal tissues, skin, or breast, among others. Finally, staging refers to the process of determining the size of cancer in the body and its localization [23]. To assess the staging of cancer, several diagnostic tests are required (X-rays, biopsies, and ultrasound, among others). In Stage 0, abnormal cells are present but have not spread to nearby tissue [24]; in Stages I, II, and III, cancer is present (the higher stage number, the larger the tumor and the more it has spread into surrounding tissues); and in stage IV, cancer has spread to distant parts of the body (metastasis) [23].

There are also other systems more precise from the medical point of view, for instance, the tumor-node-metastasis (TNM) system that is suggested by The American Joint Committee on Cancer. The TNM is updated periodically, based on advances in the understanding of cancer prognosis, to remain current and relevant for clinical practice; this manual is also described for every anatomical site $[23,25]$.

Recently, there have been other efforts to generate an integrated system to classify cancer [26]. Cancer cells are classified using the cell morphology, leaving behind the functional attributes of these cancer cells. Using techniques in biology based on genomics, transcriptomics, and proteomics, scientists can model the attributes of cancer stem cells and their potential contribution to treatment responses and metastases [26-30].

\section{Colorectal Cancer}

The name "colorectal cancer" is used to describe bowel cancer that starts in the colon or the rectum. CRC almost always develops from growths called colorectal polyps that form in the lining of the colon (adenocarcinoma in more than $95 \%$ of cases) [22,31]. After the diagnosis, the treatment depends on various factors, including the stage of cancer. In the early stages of CRC, the tumor just 
needs to be surgically removed, but in advanced stages, additional treatments may be considered, such as chemotherapy and radiation therapy, among other adjuvant therapies [31].

\section{Colorectal Cancer Treatments}

As mentioned above, CRC treatment depends on cancer staging, but it is classified into two groups, surgery and adjuvant therapy.

\subsection{Surgery}

Colorectal cancers may be cured by surgery (hemicolectomy) [2], but only if the entire tumor is localized and no cells have spread to other sites (adenocarcinoma in situ) [22,32]. Moreover, in most of the cases, complementary therapies (adjuvants) are needed before or after surgery and vary from traditional to novel. Traditional chemotherapies are based on 5-FU, which inhibits cancer cell division. Nobody doubts that traditional adjuvant treatments have improved the prognosis of patients; however, they are not beneficial for all cases. For instance, not all women with breast cancer derive benefit from 5-FU-based adjuvant chemotherapy. Many older women (age > 70) with hormone receptor-positive early stage breast cancer treated with adjuvant chemotherapy will not accrue a survival advantage [33]. For CRC, it was demonstrated that extra cycles of traditional chemotherapy, either before or after chemoradiotherapy, have been shown not to improve survival compared with chemoradiotherapy alone. An argument for less chemotherapy is also presented by results from trials investigating neoadjuvant or preoperative therapy in esophageal and gastric cancers. In randomized trials, which enrolled patients with esophageal and gastro-esophageal junction adenocarcinoma, no survival benefit with four cycles of the ECX regimen (epirubicin, cisplatin, and capecitabine) were reported beyond that achieved with two cycles of fluorouracil and cisplatin. These results support the use of a shorter duration of preoperative chemotherapy [34].

5-FU can cause local and systematic toxicity (DNA damage) to healthy cells, generating undesired side effects, and favor the mutation of them to malignant cells. These problems can be overcome by using novel approaches such as targeting specific cancer-relevant proteins (such as oncogenic tyrosine kinases), immunotherapy, and reactive oxygen species (ROS)-modulated therapies, which are more specific in generating cancer cell apoptosis and reducing the side effects associated with traditional chemotherapy $[35,36]$.

\subsection{Adjuvant Therapy}

Adjuvant therapy is defined by the United States National Cancer Institute (NCI) as "additional cancer treatment given after the primary treatment (surgery) to lower the risk that cancer will come back" [2], eliminating any residual microscopic cancer cells. Neoadjuvant therapy is an adjuvant therapy given before the primary treatment to make it more effective or easier [37]. Adjuvant therapies for CRC can be divided into five groups, i.e., radiation, hormones, targeted therapy, immunotherapy, and chemotherapy.

\subsubsection{Radiation Therapy}

Radiation therapy (RT) is the application of ionizing radiation to treat cancer. Cancer cells are more sensitive to DNA damage than normal tissue cells; this characteristic provides the therapeutic effect [38]. It is estimated than $50 \%$ of the population with cancer can benefit from this therapy [38]. For colorectal cancer, RT is used as a neoadjuvant treatment to improve patient prognosis, heightening the overall survival rate, diminishing the local recurrence rate, and improving the quality of the surgical procedures [39].

Besides some side effects-such as incontinence of the anal sphincter or urinary tract problems, vaginal dryness, and sexual dysfunction, among others-related to neoadjuvant RT, new techniques have focused efforts on modulating the beam intensity and improving the beam precision and development of delivery systems for encapsulated radionuclides (brachytherapy) [39,40]. 


\subsubsection{Hormone Therapy}

Bowel health largely depend on hormones; for instance, Jhonson et al. (2009) found that sex hormones such as estrogen and progestin are related to protective effects against CRC in menopausal women [41]. Similar results were found by Rennert et al. (2009) in 5214 women in perimenopausal/postmenopausal stages with CRC, where the use of estrogen/progestin replacement therapy reduced the risk of CRC by 63\% [41]. For men, Lin et al. (2014) found that higher levels of testosterone are related to lower risks of CRC [42]. Hormone therapy is a systemic approach with several side effects such as abdominal pain, headache, depression, acne, nausea, leg cramps, and stroke, among others $[43,44]$. The use of drug delivery systems can help in reducing the needed doses, which can lower the undesired side effects of the treatment [45].

\subsubsection{Targeted Therapy}

Targeted therapy is a type of treatment that uses drugs or other substances to identify and attack specific types of cancer cell with less harm to healthy cells. Targeted therapy may have fewer side effects than other types of cancer treatment. Targeted therapies are either small molecule drugs or monoclonal antibodies [23]. The most investigated monoclonal antibodies are bevacizumab, cetuximab, and panitumumab $[46,47]$.

Bevacizumab is a recombinant humanized monoclonal IgG antibody that selectively binds to vascular endothelial growth factor A (VEGF-A), and it demonstrates anti-tumor activity by blocking vascular endothelial growth factor receptor 2 (VEGFR2). Furthermore, patients treated with cetuximab and panitumumab showed a survival benefit in metastatic CRC [46]. Cetuximab is an anti-epithelial grow factor (EGFR) monoclonal antibody of the IgG1 class targeted against the extracellular domain of the EGFR. By binding to the EGFR, cetuximab blocks intracellular EGFR signaling and modulates tumor cell growth by inhibiting proliferation, angiogenesis, and differentiation; stimulating apoptosis; and preventing metastasis. Panitumumab is a fully human, monoclonal antibody targeting the EGFR with high affinity. Its mechanism of inhibiting the EGFR signaling pathway is similar to that of cetuximab, as described above [46]. Nevertheless, to improve the efficacy of the treatment, the therapy should be complemented with cytotoxic chemotherapy using 5-FU [48,49].

\subsubsection{Immunotherapy}

Immunotherapy was first proposed in 1909 by Nobel Prize winner Paul Ehrlich. The idea behind it is that immune cells can control malignant cells and eradicate cancers before they manifest clinically [35]. However, in spite of several mechanisms active in the immune system to recognize and eliminate tumor cells, some variants of these cells selectively acquire increased resistance against immune responses. Thereafter, resistant cells continue to grow, evading the immune responses, and tumor cells develop resistance against both innate and adaptive immune mechanisms (cancer immunoediting) [35]. To avoid cancer immunoediting, patients can be vaccinated (monoclonal antibodies, adaptive T cells, DNA viral vectors, heat shock proteins, and dendritic cells, among others [35,50-54]) to raise specific immune responses. Moreover, this therapy is followed in parallel with another adjuvant therapy to potentiate the immune system [35].

\subsubsection{Chemotherapy}

Chemotherapy for cancer treatment uses drugs (plant-derived or synthetic) called cytostatic drugs (cytotoxic chemotherapy), which aim to stop cancer cells from continuing to divide uncontrollably [55].

It is estimated that $20-30 \%$ of newly diagnosed patients with CRC present with unresectable metastatic disease. In addition, a considerable proportion of patients (40-50\%) experience disease recurrence after surgical resection or develop metastatic disease, typically in the liver or lungs [56]. To improve the life prognosis of those patients, several drugs have been developed, such as 5-FU, which is considered the gold standard for CRC chemotherapy [56]. 
5-FU was developed in 1957 by Charles Heidelberger and colleagues at the University of Wisconsin, who observed that tumor tissues preferentially used uracil-type molecules for nucleic acid biosynthesis and postulated that a fluorouracil analog would be easily taken up by cancer cells. Likewise, it would inhibit tumor cell division by blocking the conversion of deoxyuridine monophosphate (dUMP) to deoxythymidine monophosphate (thymidylate) [56].

From 1957 to date, 5-FU has been complemented with other adjuvants to improve the overall survival of patients. For instance, Petrelli et al. (1987) found that mixing 5-FU with leucovorin at $500 \mathrm{mg} / \mathrm{m}^{2}$ in metastatic patients improved overall survival [57]. Goldberg et al. (2004) studied the efficacy in metastatic CRC patients of 5-FU plus leucovorin, irinotecan, and oxaliplatin combinations (FOLFOX) in 795 patients, finding a median survival rate of 19.5 months, which is 35\% higher compared with that with other treatments [58], and recently, Magne et al. (2012) investigated the efficacy of cetuximab with continuous or intermittent 5-FU, leucovorin, and oxaliplatin (Nordic FLOX) treatment versus FLOX alone in the first-line treatment of metastatic CRC, finding an overall survival of up to 20.4 months [59].

Today, there is a growing interest in researching natural drugs as adjuvants for CRC; most of them act against reactive oxygen species (ROS). Reactive oxygen species (ROS) include oxygen molecules, superoxide anion radicals, hydroxyl free radicals, and hydrogen peroxide. ROS are generated in the mitochondrial respiratory pathway. Although an increase in the level of intracellular ROS leads to oxidative stress and DNA damage, the effects of ROS are normally balanced by antioxidants, such as reduced glutathione (GSH), ascorbic acid, and uric acid [60]. Disruption of the oxidant-antioxidant balance through alterations to cellular homeostasis or the defective repair of ROS-induced damage is involved in carcinogenesis. Furthermore, it is known that anticancer drugs induce oxidative stress in patients with cancer being treated with chemotherapy [60]. To reduce oxidative stress, investigations are focusing on natural antioxidants. In Table 2, the latest studies for CRC using natural antioxidants are presented. Natural antioxidants are presented as extracts (fruits, plants, and coffee, among others) or polyphenol fractions from those extracts [61].

Table 2. Natural antioxidants for the prevention and treatment of colorectal cancer; recent reports from 2015 to 2019.

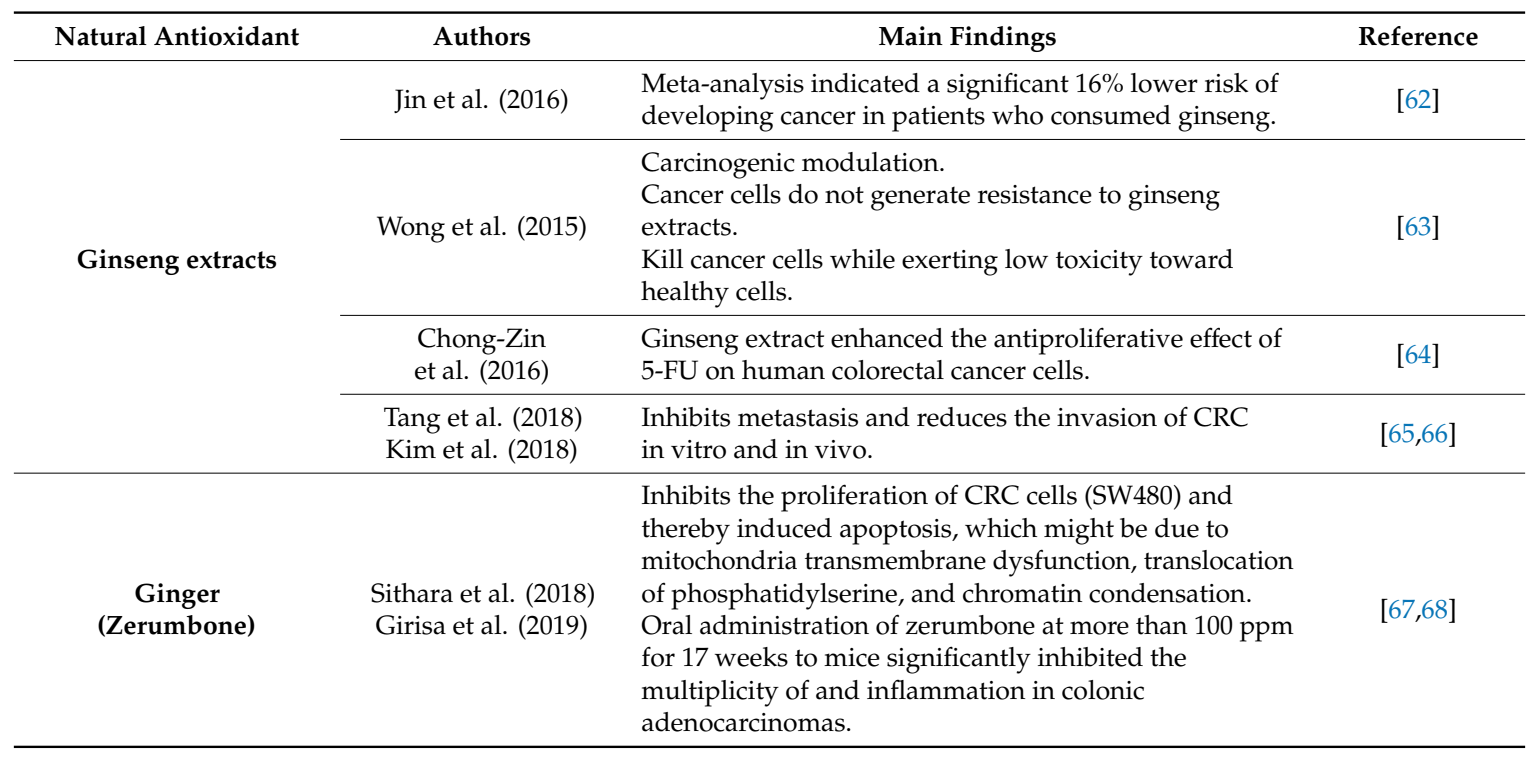


Table 2. Cont.

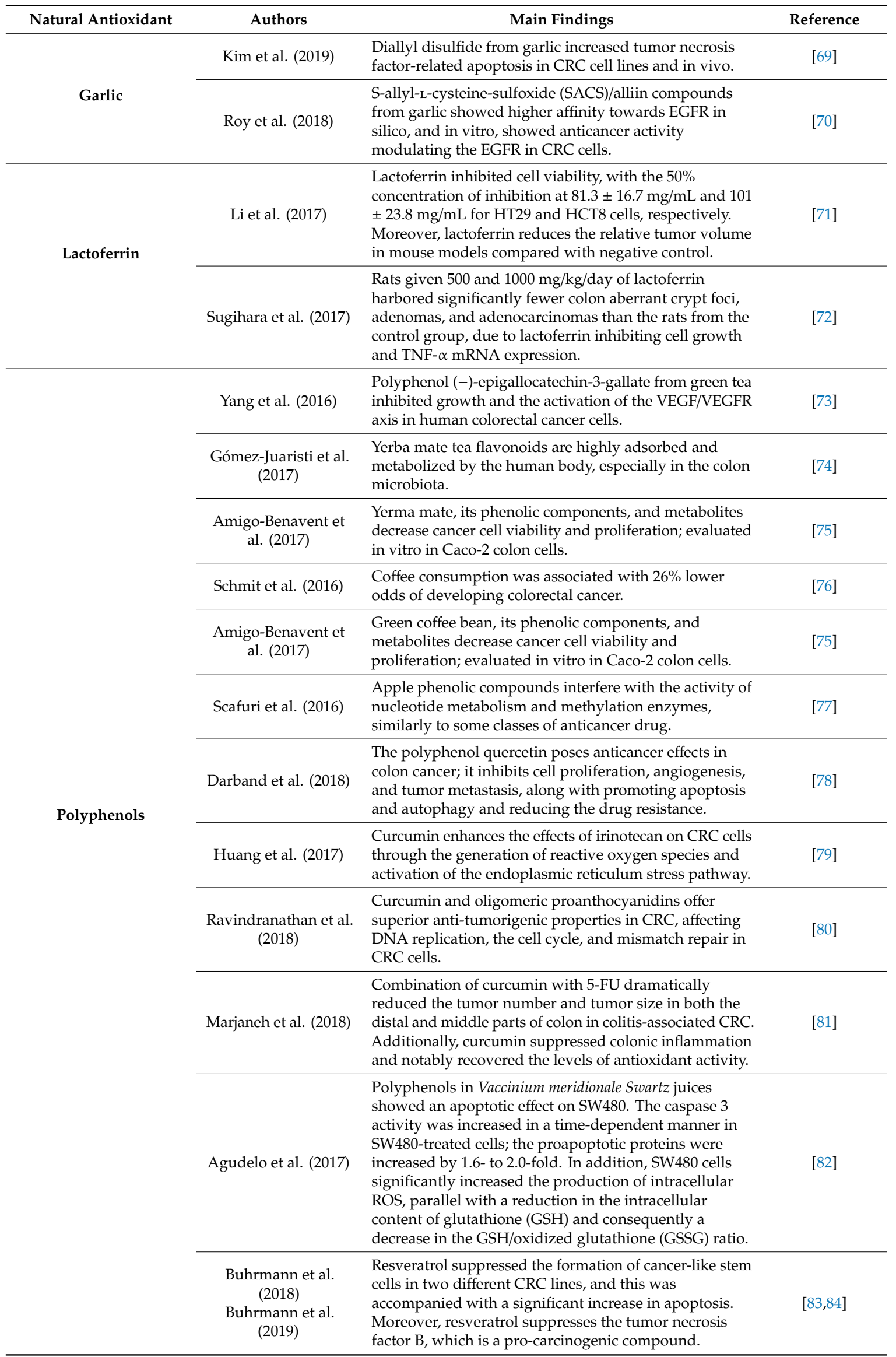


Table 2. Cont

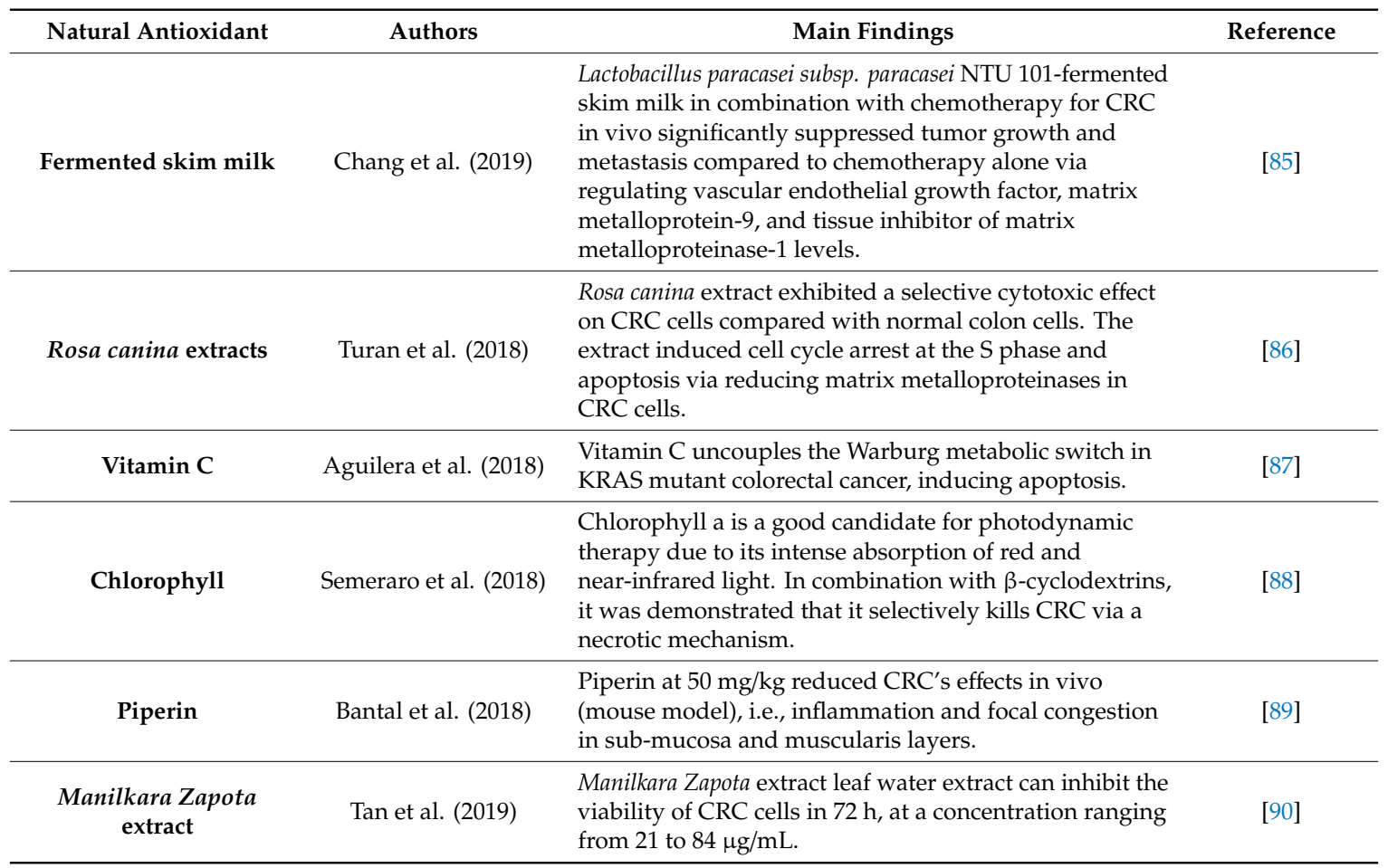

Accordingly, most of the antioxidants in Table 2 are polyphenols, due to most plant-based food naturally containing them. The basic monomer in polyphenols is a phenolic ring, and generally, these are classified as phenolic acids and phenolic alcohols [61]. Polyphenol consumption is strongly associated with a low cancer risk. For instance, the Mediterranean diet (rich in olive oil polyphenols [91]), reduces the risk of CRC by approximately $4 \%$ [92]. However, $4 \%$ is still modest; thus, polyphenols are extracted to present higher antioxidant activity and consequentially higher anticancer effects. Moreover, the colorectal anticancer effect can be potentiated if the antioxidant is supplied using a drug delivery system [93].

\section{Polymer-Based Drug Delivery Systems for Adjuvants for Colorectal Cancer}

Ideally, drugs would target the cancer cells with the exact therapeutic concentration. However, drug delivery is not easily controlled. Drug release rates, cell- and tissue-specific targeting, and drug stability are difficult to predict [93]. Furthermore, when targeting colon cells, the drug may avoid degradation and/or be released early, which would reduce its therapeutic effect.

Likewise, natural and synthetic compounds can be easily degraded by air, UV light, and moisture, and lose their antioxidant potential [94]. Thus, encapsulation is important for improving their stability and, overall, generating long-term desorption profiles that improve the CRC adjuvant treatments.

\subsection{Nanoencapsulation}

Nanoencapsulation is a nanostructured drug delivery system (10-1000 $\mathrm{nm}$ [95]) that can be loaded with small molecules or macromolecules, thus acting as a vehicle for chemotherapeutic drugs. Such materials are able to transport chemotherapeutic molecules to the desired area, increasing the drug concentration, to be subsequently released in a controlled manner. A great number of nanoformulations - such as liposomes, micelles, nanoemulsions, and polymeric nanoparticles, among others-have been reported as drug delivery systems to be applied in cancer treatment [96-99].

Nanoencapsulation can be performed to generate two categories of nanodevice (see Figure 5), nanocapsules and matrixial nanomaterials. In the nanocapsules group, the chemotherapeutic drug 
is surrounded by a wall or shell material to generate spheres or irregular nanocapsules where the chemotherapeutic drug can be mononucleated (a single core) or polynucleated (multicore) [100-102].
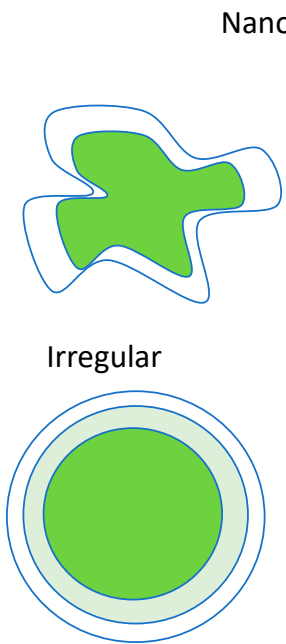

Multiwall

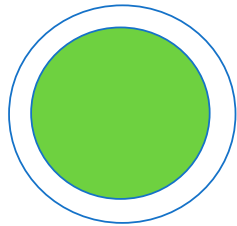

Mononuclear

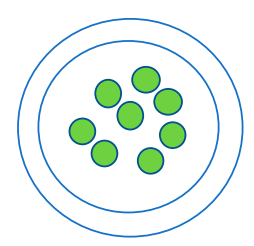

Polynuclear

Chemotherapeutic drugs

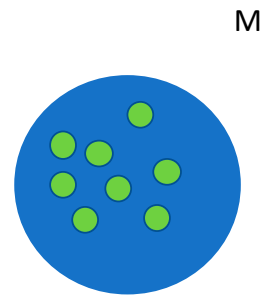

Nanosphere

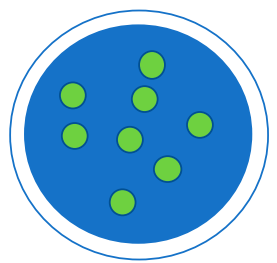

Coated nanoparticle

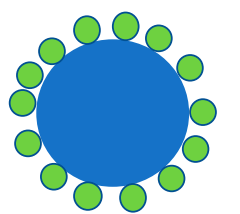

Bioactive coated nanoobject

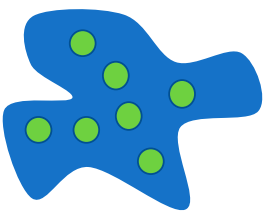

Irregular nanoparticle

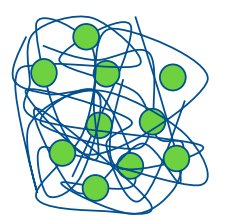

Nanostructure fibrous particles

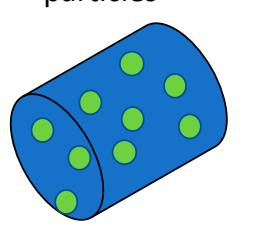

Composite nanofiber

Figure 5. Nanodevices for the encapsulation of chemotherapeutic drugs/antioxidants.

Matrixial nanomaterials are more varied. Generally, the bioactive compound (chemotherapeutic drug) is embedded or superficially adsorbed in a polymer matrix. The polymer matrix can be configured in different forms, nanospheres, irregular nanoparticles, and nanofibers, among others [103-105]. Likewise, the nanoparticle may or not may be coated by another polymer. The nanoparticle can be solid or nanostructured by fibers [106,107].

The techniques used for achieving nanoencapsulation are complex. This is mainly due to the difficulty in attaining the complex morphology of the capsule and core material and the demands of controlling the release rate of the nanocapsules [108]. Various techniques have been developed and used for nanoencapsulation purposes. For instance, emulsification, coacervation, inclusion complexation, solvent evaporation, nanoprecipitation, and supercritical fluid techniques can produce capsules in the nanometer range $(10-1000 \mathrm{~nm})[95,108]$. Most of the documents regarding encapsulation relate to particles between 100 and $1000 \mathrm{~nm}$. However, there also some reports with capsules ranging from 10 to $100 \mathrm{~nm}$.

\subsection{Release Mechanism}

Nanodevices (nanocapsules and matrixial nanomaterials) can provide several forms of release for the chemotherapeutic drugs (see Figure 6). Drugs can be desorbed from the matrix or core reservoir (nanocapsules) because of a concentration gradient that can be assisted by swelling or material relaxation, facilitating the release of the bioactive component [109]. 


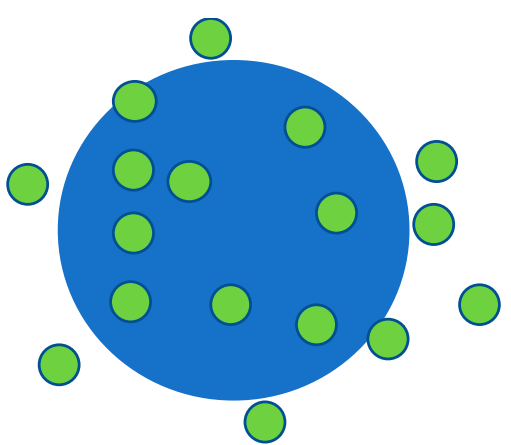

Desorption

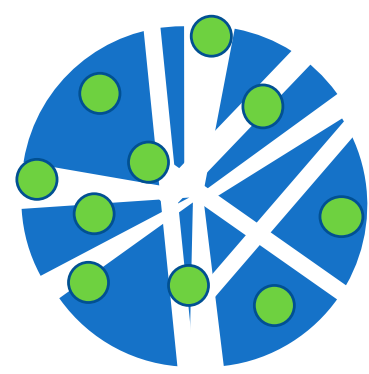

Degradation

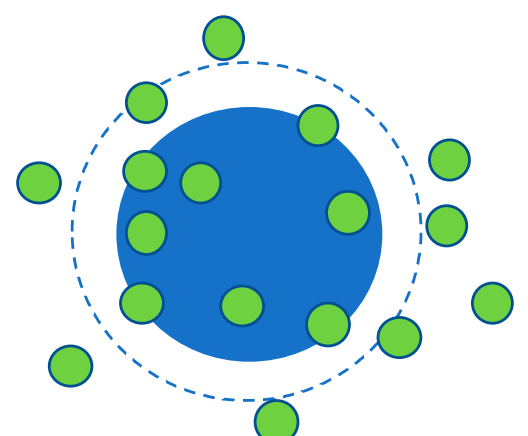

Erosion/dissolution

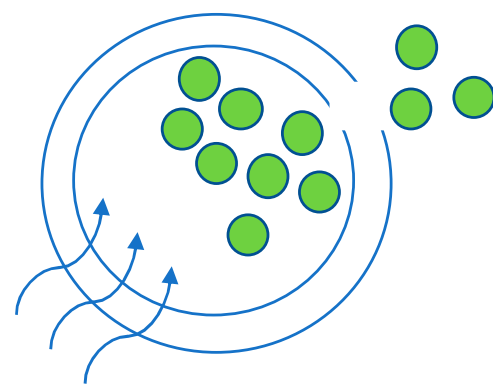

Osmotic Pump

Figure 6. Drug-releasing mechanism of chemotherapeutic drugs.

The erosion/dissolution implies the loss of the shell or matrix integrity to favor the diffusion of the bioactive component. The erosion/dissolution of the nanodevice can be triggered by $\mathrm{pH}$ changes and water content, among others. Usually these systems deliver the bioactive compound quickly once the capsule is in contact with the target environment. Otherwise, the degradation mechanism tends to be a slow as it is mediated by enzymatic reactions [110,111].

An osmotically active drug can be delivered using an osmotic pump, in which the bioactive component is pushed away by a fluid that goes into the capsule via a semipermeable membrane and force the drug to pass throughout an orifice [112].

Along with the nanodevice type, the interaction of the biomaterial/bioactive compound modulates the releasing profile. Bioactive components for CRC treatment are complex; for instance, antioxidants poses aromatic rings with hydroxyl lateral groups, conferring to them a hydrophilic nature [113], and hydroxyl groups can easily generate hydrogen bond interactions with biomaterials. Antioxidants of high molecular weight present an amphiphilic nature, with hydrophilic and lipophilic zones such in the case of vitamin E and carotenoids [114], which can interact with either polar or nonpolar polymers.

Plant extracts contains several bioactive compounds (mixtures of hydrophilic and lipophilic compounds). Nevertheless, most CRC adjuvant extracts are, in general, hydrophilic in nature and water-soluble $[90,115-117]$ and thus can interact with hydrophilic polymers. Likewise, synthetic bioactive compounds have an amphiphilic nature; for instance, $5-\mathrm{FU}$ is a pyrimidine with oxygen and flour lateral groups, conferring it with a hydrophilic nature, but 5-FU can present resonance diminishing its water solubility [118]. According to the above, given the diversity of CRC adjuvants, several polymer-based biomaterials have been used for generating nanodevices for drug delivery systems.

\subsection{Polymers for Oral Drug Delivery Systems}

Biomaterials have improved the delivery and efficacy of a range of pharmaceutical compounds. In particular, polymer- and lipid-based materials have been designed to release therapeutics for extended periods of time and for targeting specific locations within the body, thereby reducing the toxicity to the 
patient whilst keeping the therapeutic effect [110]. Lipid-based drug delivery systems are beyond of the goals of this paper; these formulations types are reviewed in the following references [119-121]. For polymer drug delivery, the oral route has been proven to be most convenient route for chronic drug therapy [119]. For instance, in studies of CRC patients, it has been proven that the oral administration of adjuvant treatments is most suitable for the patient and cost-saving for health systems $[122,123]$. However, oral administration is challenging for CRC as the drug needs to be protected during passage through the digestive tract before proper delivery. For this application, polymers are advantageous due to their processability at the nanoscale, their wide range of functional groups, and the possibility of generating mixtures, composites, and copolymers, among others [124], favoring the protection of the drug and its delivery profile.

Drug delivery polymers for colorectal cancer can be classified according to polymer nature, into non-charged polymers and charged polymers (anionic, cationic, and zwitterionic), as presented in Figure 7. Non-charged polymers cannot be charged via dissociation; thus, they are strongly stable at any $\mathrm{pH}$ value, and they can interact via hydrogen bonding and Van der Waals interactions. Alternatively, charged polymers can generate anionic, cationic, or zwitterionic charges on their surface and can switch from neutral to charged, depending on the hydrogen potential of the surrounding environment. The switching from neutral to charged will influence the chain polymer organization. For instance, Han et al. (2016) found that the carboxylic lateral groups of polyacrylic acid copolymers induces polymer changes in terms of roughness, thickness, and porosity, from $\mathrm{pH} 5.5$ to 9 [125]. Those systems have the advantage of modulating the drug release by $\mathrm{pH}$, as presented in the gastrointestinal fluids. The interaction with these polymers is more likely to be ionic, which is stronger, but requires at least polar or ionic charges in the bioactive compounds.

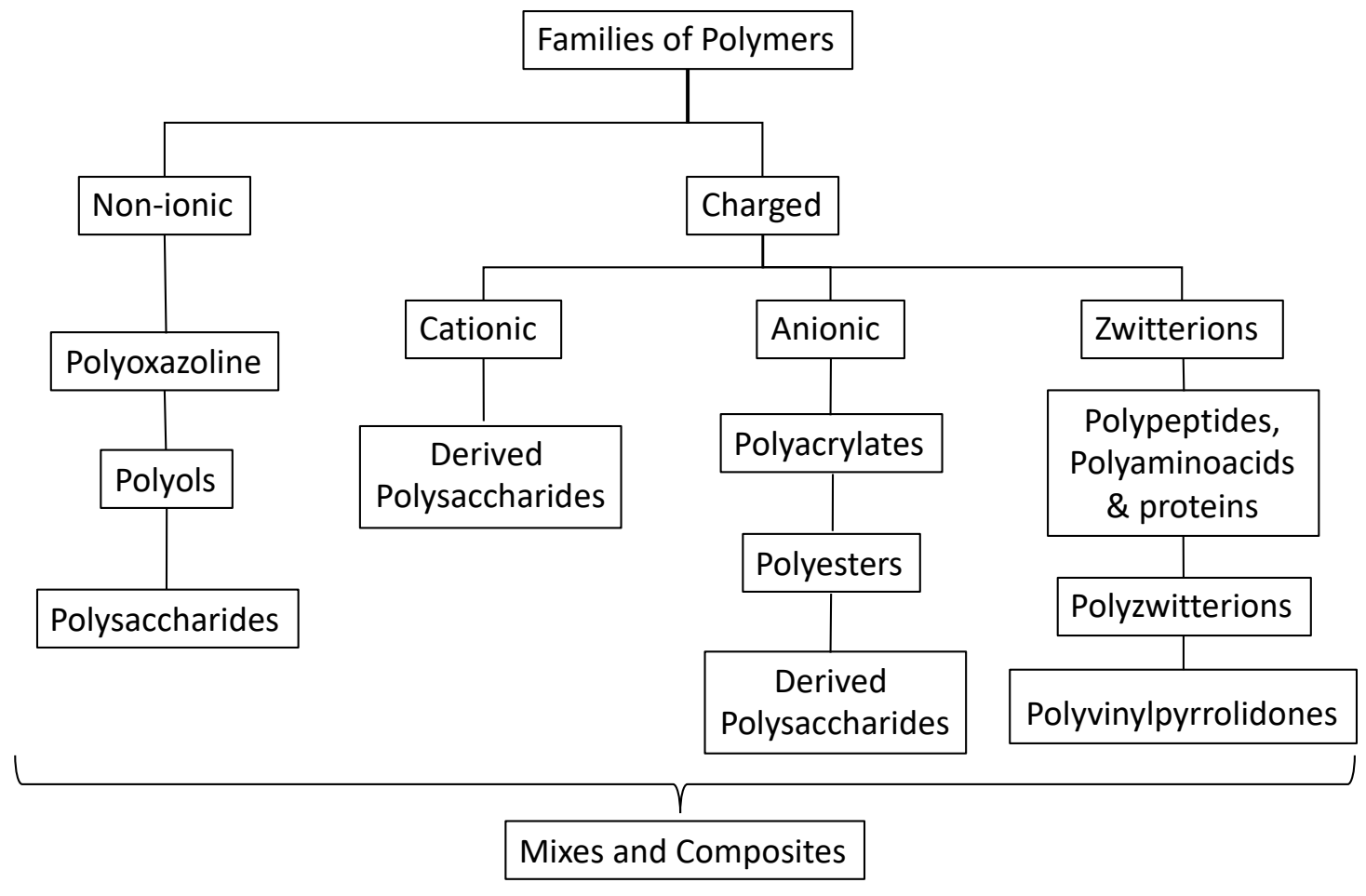

Figure 7. Polymer families for drug delivery systems of antioxidants for CRC.

Mixtures and composites are alternative strategies for creating a synergistic response in the system [126,127]. In the following sections, the strategies for each polymer type in drug delivery systems for CRC are described. 


\subsection{Polymers for Encapsulating Antioxidants for Colorectal Cancer}

Antioxidants for drug delivery have more than 4600 documents indexed in Scopus, with an accelerated growth from 2000 to date. From those, around 44.6\% include the word "polymer", which hints at the relevance of creating polymer-based drug delivery systems to protect these compounds. For encapsulating antioxidants, all polymer families have been used for the drug delivery of these compounds.

\subsubsection{Polysaccharides and Derived Polysaccharides}

Polysaccharides are carbohydrate polymers composed of long chains of monosaccharides, such as glucose, fructose, and galactose, among others [128]. Polysaccharides can respond to $\mathrm{pH}$, colon enzyme degradation, or peristaltic movement. For instance, chitosan can response to $\mathrm{pH}$ changes, starches can be degraded by amylase enzymes, and ethyl cellulose can be broken by colon waves [129]. Polysaccharides have garnered attention because, like antioxidants, they come from natural sources, allowing the development of bio-based therapies for CRC. Antioxidants have been successfully encapsulated using polysaccharides for nanocapsules such as cellulose, chitosan, and alginate, among others.

Cellulose is the most abundant polymer on earth; it is composed of $\beta 1-4$ linked $\mathrm{D}(+)$ glucose [124,130,131]. Cellulose and its derivatives have been reported as carriers of antioxidants. For instance, Sunnasee et al. (2019) grafted $\beta$-cyclodextrins in cellulose nanocrystals, demonstrating that this system is not immunogenic and does not induce oxidative stress in the cell, thus it is safe for intracellular drug delivery [132]. Li et al. (2019) developed a nanoformulation of quercetin and cellulose nanofibers with sustained antioxidant activity. The nanocellulose fibers were an effective nanocarrier of the antioxidant with a loading capacity of $78.91 \%$ and encapsulation efficiency of $88.77 \%$; moreover, the quercetin delivery profile was extended to higher times [133]. Ching et al. (2019) encapsulated curcumin in cellulose nanocrystals (via acid hydrolysis), adding surfactants to improve the loading capacity of the release profile of the antioxidant [134]. Ngwabebhoh et al. (2018) developed a Pickering suspension for encapsulating curcumin using cellulose nanocrystrals [106], finding that the capsules were stable for up to 8 days at different pHs [106]. However, the application was directed to antimicrobial properties instead of antioxidants for CRC.

Chitosan is a polysaccharide obtained from chitin deacetylation, composed of $\beta-(1 \rightarrow 4)$-linked D-glucosamine (deacetylated unit) and N-acetyl-D-glucosamine (acetylated unit) [135]. It is a cationic polymer that responds to $\mathrm{pH}$ changes and can be converted into hydrogels, making this polymer attractive for the drug delivery of antioxidants. For instance, Kumar et al. (2015) encapsulated naringenin (polyphenol) using chitosan nanocapsules. Their studies proved that encapsulated naringenin has a better anticancer effect than free naringenin [136]. Jeong et al. (2016) crosslinked chitosan with resveratrol modified with phospholipids to improve its oral bioavailability and low water solubility. The researchers found an encapsulation efficiency of up to $85.59 \%$, and an in vitro drug release study suggested a slow and a sustained release governed by diffusion [137].

Shi et al. (2017) encapsulated $\beta$-carotene and anthocyanin in (2,2,6,6-Tetramethylpiperidin-1 -yl)oxyl (TEMPO)oxidized polysaccharides, specifically Konjac Glucomannan, in which some polysaccharides' hydroxyl lateral groups were converted into carbonyl groups, and then the spheres were coated with chitosan. The advantage of the system was its ability to generate oil-water stable systems and to retain the antioxidants at gastric $\mathrm{pH}$ values; moreover, the capsules exhibited anticancer effects [138].

Alginates are salts derived from alginic acid, in which the polymer has a carbonyl lateral group liked to a glucose unit, making the polymer negatively charged [139]. Sookkasem et al. (2015) developed novel alginate beads for encapsulating curcumin for colon target therapy; the capsule was able to prevent release in the upper gastrointestinal tract and immediately release the drug upon the arrival of the beads in the colon [139]. However, the approach of Sookkasem et al. was not at the nanoscale; the alginate beads had a diameter in millimeters (macroscale). Similarly, Wang et al. (2019) developed a macroscale capsule but using $\mathrm{ZnO}$ instead of $\mathrm{Ca}^{2+}$ as the crosslinking agent to improve the 
release profile to a longer time [140]. Approaches at the nanoscale for this polymer have been tested using mixtures and composites, especially with chitosan [141,142], as reported in the following sections.

Maltodextrin $(\alpha 1-4 \mathrm{D}(+)$ glucose) is a low molecular weight polysaccharide that has been broadly used for the encapsulation of food and pharmaceutical ingredients [143]. Ming et al. (2018) encapsulated red ginseng extract, generating a water/oil emulsion, and then coated it with maltodextrin using spray-drying. The researchers found particles ranging from 58 to $400 \mathrm{~nm}$ and optimized the conditions to produce them [143]; however, they did not evaluate the release or anticancer effects of the produced nanocapsules.

Pan et al. (2018) encapsulated curcumin in soybean polysaccharides (mixture of cellulose, xylogalacturonan, and arabinogalactan, among others), polysaccharides that easily link lipophilic compounds. The capsules were stable at a pH ranging from 2.0 to 7.0 [144]. Li et al. (2017) encapsulated phenolic acid antioxidants to prove the effectiveness of producing hollow Arabic gum and short linear glucans from starch templates. Hollow nanocapsules enhanced the antioxidant activity of the phenolic acids and improved the stability of their antioxidant activity in challenging environments with high salt concentrations, and when exposed to UV radiation and high temperatures [145].

Assis et al. (2017) incorporated lycopene nanocapsules in starch films to generate an edible film material, but the application was focused on packaging instead of biomedical efficacy [146]. Amah et al. (2019) encapsulated catechin in starch-based nanoparticles, providing protection to the catechin against the harsh gastric environment and helping to retain its bioactive properties during an in vitro digestion process [147]. Jana et al. (2017) reviewed different strategies for generating three-stimuli-responsive guar gum composites $(\mathrm{pH}$, time, and enzymes) for colon-specific drug delivery [148]. Finally, Saffarzadeh-Matin et al. (2017) prepared an apple pomace polyphenolic extract and encapsulated it in maltodextrin in nanocapsules of $52 \mathrm{~nm}$ diameter, optimizing the loading efficiency of the process [149].

\subsubsection{Polyacrylates}

Polyacrylates are polymers derived from acrylic acid via free radical polymerization. Nevertheless, Garay-Jimenez et al. (2011) reported an alternative method for producing polyacrylate nanoparticles between 40 and $50 \mathrm{~nm}$ by emulsion polymerization using a 7:3 mixture of butyl acrylate and styrene in water containing sodium dodecyl sulfate as a surfactant and potassium persulfate as a water-soluble radical initiator. The resulting method seemed promising for the encapsulation of bioactive agents of interest in the biomedical field [150].

Polyacrylates are anionic polymers that present maximum swelling at $\mathrm{pH}$ neutral to alkaline, and minimum under acidic conditions, making them ideal for colon-specific drug delivery systems [151].

Feuser et al. (2016) modified with folic acid polymethyl meta acrylate and ferrous sulfate to produce superparamagnetic nanoparticles with excellent colloidal stability and high efficacy in encapsulating lauryl gallate (antioxidant). The release profile of lauryl gallate showed an initial burst effect followed by a slow and sustained release, indicating a biphasic release system. The lauryl gallate loaded in superparamagnetic polymethyl methacrylate (PMMA) nanoparticles did not have any cytotoxic effects on non-tumoral cells. Moreover, the folic acid promoted folate receptor-mediated endocytosis in tumoral cells, enhancing the anticancer effect of lauryl gallate [152].

Ramalingam et al. (2018) loaded curcumin in electrospun fibers to generate a dressing for the treatment of skin cancer. The dressing induced cell proliferation and free radical scavenging activity and up-regulated the expression of CDKN2A in A375 melanoma cells. The cell death of A375 melanoma cells was dose- and time-dependent, which indicates that treatment with curcumin loaded in the nanofibers inhibited the growth and induced the cell death of the skin cancer cells [151].

Ballestri et al. (2018) developed a synthetic antioxidant (porphyrin) and encapsulated it in polymethyl methacrylate (PMMA) core-shell nanoparticle $(70 \mathrm{~nm}$ diameter) for photodynamic cancer therapy. Photodynamic cancer therapy uses a light to activate an antioxidant compound. The capsule 
protected porphyrin against unwanted bleaching while preserving the anticancer activity, which was similar to that of free porphyrin under in vitro testing [153].

Recently, Sobh et al. (2019) synthesized a multi-walled carbon nanotube (MWCNT)/Poly(methyl methacrylate-co-2-hydroxyethyl methacrylate) P(MMA-co-HEMA) nanocomposite loaded with either curcumin or its water-soluble derivative via an in situ microemulsion polymerization technique by using different ratios of multi-walled carbon nanotube MWCNT to drug. Curcumin could be loaded in higher amounts with high entrapment efficiency values with improved thermal stability with an increased MWCNT ratio. The in vitro drug release studies of the nanocomposite showed a prolonged controlled release in the intestinal fluid at $\mathrm{pH} 7.4$ and that $\leq 8 \%$ of the drug was lost in the stomach fluid at $\mathrm{pH} 1.2$ [154].

Sunoqrot et al. (2019) developed a pH-sensitive polymeric nanoparticle of quercetin as a potential colon cancer-targeted nanomedicine. Quercetin is an abundant plant polyphenol with demonstrated efficacy in CRC. The researcher developed polymeric nanoparticles of quercetin based on the $\mathrm{pH}$-sensitive polymer methacrylic acid and copolymers (Eudragit ${ }^{\circledR} \mathrm{S} 100$ ) to achieve colon $\mathrm{pH}$-specific drug release. The researchers found nanoparticles with a mean diameter of $66.8 \mathrm{~nm}$ and a partially negative surface charge of $-5.2 \mathrm{mV}$. In vitro release testing showed a delay in drug release in acidic $\mathrm{pH}$ but complete release within $24 \mathrm{~h}$ at $\mathrm{pH}$ 7.2. A cytotoxicity assay on CT26 murine colon carcinoma cells displayed a significantly higher potency of encapsulated quercetin (IC50 $=0.8 \mu \mathrm{M}$ ) than free quercetin $($ IC50 $=65.1 \mu \mathrm{M})[155]$.

\subsubsection{Polyols}

Polyols are polymers with hydroxyl groups [156]. A representative polymer of this family is the polyvinyl alcohol (PVA), which is synthesized by the hydrolysis of polyvinyl acetate $[157,158]$. PVA is a water-soluble polymer that can generate hydrogels by chemical or physical crosslinking [159]. Recent advances are presented below.

Li et al. (2019) improved the solubility of curcumin using D- $\alpha$-Tocopherol polyethylene glycol 1000 succinate (TPGS), a water-soluble derivative of vitamin E that acts as a surfactant with the ability to form micellar nanoparticles in water. More importantly, TPGS acts as a potent antioxidant. The complex TPGS/curcumin was encapsulated using PVA, in which were obtained stable nanoparticles of $12 \mathrm{~nm}$ diameter. The nanoparticle satisfactorily released curcumin in simulated colonic and gastric fluids; furthermore, the nanoparticles decreased intracellular ROS levels and apoptosis and inhibited the migration of HT-29 human colon cancer cells more potently than free curcumin. The pharmacokinetic analysis demonstrated that the nanocapsules were more bioavailable than free curcumin after oral administration to rats [160].

Wen et al. (2019) developed a core-shell electrospun nanofiber, core (PVA and phycocyanin), and shell (Polyoxyethylene) for the targeted therapy of CRC. Phycocyanin (PC), a water-soluble biliprotein (antioxidant), exhibits potent anti-colon cancer properties. The PC-loaded electrospun fiber mat inhibited HCT116 cell growth in a dose-dependent and time-dependent manner. In particular, the PC-loaded mat exerted its anticancer activity by blocking the cell cycle at the G0/G1 phase and inducing cell apoptosis, involving a decrease in Bcl-2/Bax, the activation of caspase 3 , and the release of cytochrome c [161].

Golkar et al. (2019) fabricated via electrospinning, Plantago major Mucilage (PMM) blended with PVA, in order to produce an electrospun nanofiber. The researchers optimized the electrospinning parameters (voltage, tip-to-collector distance, feed rate, and PMM/PVA ratio) to obtain nanofibers with an average diameter of $250 \mathrm{~nm}$. The viscosity, electrical conductivity, and surface tension of the $\mathrm{PMM} / \mathrm{PVA}$ solution were $550 \mathrm{Cp}, 575 \mu \mathrm{S} / \mathrm{cm}$, and $47.044 \mathrm{mN} / \mathrm{m}$, respectively [162]. The systems seem promising for biomedical applications. However, the researchers did not evaluate the effects of the fibers for CRC treatment. 


\subsubsection{Polyzwitterions}

Polyzwitterions are a class of polymers consisting of zwitterionic moieties (anionic and cationic groups) as monomers. Poly(sulfobetaines), poly(carbobetaines), and poly(phosphobetaines) are representatives of a special class of polyzwitterions [163]. Gromadzki et al. (2017) developed a core-shell nanocapsule consisting of a dimer fatty acid-based aliphatic polyester core and zwitterionic poly(sulfobetaine) shell for the controlled delivery of curcumin, obtaining nanoparticles of $<100 \mathrm{~nm}$ in size with an encapsulation efficiency of $98 \%$. The researchers evaluated free and encapsulated curcumin for cytotoxicity and antioxidant activity in a panel of human cell lines and rat liver microsomes, respectively. Encapsulated curcumin had superior cytotoxic and antioxidant activity versus the free drug. In addition, cell viability experiments with non-loaded nanoparticles, both coated and noncoated, demonstrated that the developed nanoparticles are nontoxic, making them potentially suitable candidates for systemic passive targeting in cancer therapy, namely for the treatment of solid tumors exhibiting a high tumor accumulation of the capsules due to enhanced permeability and retention effects [164].

\subsubsection{Polyoxazoline}

Poly (2-oxazoline) (POZ) is a class of polymers formed by cationic ring-opening that were first identified and synthesized over 50 years ago. These polymers are nonionic, biostable, and water-soluble, and some are polar organic solvents. POZ can be synthesized from readily available non-toxic materials. The interest in using POZ in medical devices and drug delivery is very recent, and their application in multiple platforms is now being recognized by drug delivery scientists [165]. Although there is limited literature about the use of POZ for cancer treatment, some formulations for the treatment of skin cancer are reported. For instance, Simon et al. (2019) developed ointments with quercetin (core) encapsulated in POZ (shell). The POZ produced a stable formulation of spherical nanocapsules of $18 \mathrm{~nm}$ in size. Moreover, a good quercetin encapsulation ( $94 \% \pm 4 \%$ ) efficiency was observed with these nanosystems, allowing its homogeneous distribution in the nanocapsule.Therefore, Q-MM can be used as a reservoir of quercetin. Once loaded, quercetin's impact on cancer cell viability was doubled while its antioxidant efficacy was preserved [166]. Accordingly, POZ are an alternative for the encapsulation of antioxidants; hopefully, some new advances in oral drug formulations will be presented in the following years that can be used for CRC.

\subsubsection{Polypeptides and Polyaminoacids}

Polyaminoacids (PAA) and polypeptides (PPD) are polydisperse structures formed by the condensation of amino acid monomers through amide bonds that, contrary to proteins, cannot fold into globular or fibrillar structures [167]. In addition, they can carry versatile reactive functional groups on their side chains (carboxylic acid, hydroxyl, amino, and thiol groups) that allow for a variety of chemical modifications and compatibility with a wide range of bioactive compounds. Some outstanding nanocapsules of polyaminoacids have been developed for cancer treatment. For instance, Choi et al. (2018) encapsulated Celastrol (antioxidant) in PEGylated polyaminoacid-capped mesoporous silica nanoparticles for mitochondria-targeted delivery in solid tumors [107], and Patsula et al. (2019) modified maghemite nanoparticles with poly ( $\mathrm{L}$ ) poly(L-lysine) to protect the iron dioxide core from reaction with the encapsulated antioxidant (epigallocatechin-3-gallate from tea) and to promote the internalization of the nanoparticle of the system into the cancer cell [168].

PPD are special polymers that exhibit antioxidant properties themselves; in Table 3 , some recent studies are presented. 
Table 3. Recent advances in polypeptides (PPD) with antioxidant effects for CRC.

\begin{tabular}{|c|c|c|c|}
\hline Polypeptide & Authors & Main Findings & Reference \\
\hline $\begin{array}{l}\text { Arca subcrenata } \\
\text { Polypeptides }\end{array}$ & Hu et al. (2019) & $\begin{array}{l}\text { Arca subcrenata polypeptides (PAS) inhibited the growth of } \\
\text { HT-29 cells with an LC50 value of } 117 \mu \mathrm{g} / \mathrm{mL} \text { after } 48 \mathrm{~h} \\
\text { treatment, and significantly suppressed the tumor } \\
\text { growth in nude mice bearing xenografted HT- } 29 \text { cells at } \\
\text { a dosage of } 63 \mathrm{mg} / \mathrm{kg} \text {, with little influence on normal } \\
\text { colon cells and normal colonic mucosa. PAS were then } \\
\text { inspiringly found to induce apoptosis and G2/M phase } \\
\text { arrest in HT-29 cells. The effect's mechanism involved in } \\
\text { the inhibition of IGF-1/IGF-1R signaling activation, } \\
\text { which was responsible for inactivating the downstream } \\
\text { Akt/mTOR pathway. PAS significantly inhibited the ATP } \\
\text { production of HT- } 29 \text { cells both in vitro and in vivo. }\end{array}$ & [169] \\
\hline $\begin{array}{l}\text { Legume Seed } \\
\text { Polypeptides }\end{array}$ & Lima et al. (2016) & $\begin{array}{l}\text { Albumin and globulin fractions from legume seeds were } \\
\text { screened for MMP-9 inhibitors (enzymes related to } \\
\text { cancer growth and metastasis). Lupin seeds contain the } \\
\text { most efficient MMP-9 inhibitors of all legume seeds } \\
\text { analyzed, inhibiting both gelatinases and HT29 } \\
\text { migration and growth, while pea seeds showed no effect. } \\
\text { Results reveal legume protein MMPIs as novel } \\
\text { metalloproteinase inhibitors of possible pharmacological } \\
\text { interest. }\end{array}$ & [170] \\
\hline Black Soybean Peptides & Chen et al. (2019) & $\begin{array}{l}\text { The peptide fractions that were collected in each step } \\
\text { were tested for their antioxidant capacity and anticancer } \\
\text { activities against cancer cell lines. The most active } \\
\text { fraction with a molecular weight of } 455.0 \mathrm{Da} \text { showed the } \\
\text { highest free radical scavenging and hydroxyl radical } \\
\text { scavenging activity with LC } 50 \text { values of } 0.12 \text { and } 0.037 \\
\mu \mathrm{M} \text {, respectively. Moreover, it showed high cytotoxic } \\
\text { potential against cancer cells. The amino acid sequence } \\
\text { was identified as Leu/Ile-Val-Pro-Lys (L/I-VPK). }\end{array}$ & [171] \\
\hline $\begin{array}{c}\text { Sweet Potato Protein } \\
\text { Hydrolysates }\end{array}$ & Zhang et al. (2018) & $\begin{array}{l}\text { Six sweet potato protein hydrolysates }(\mathrm{SPPH}) \text { showed } \\
\text { certain antiproliferative effects on HT-29 cells. } \\
\text { Specifically, Alcalase exhibited the highest } \\
\text { antiproliferative effect with the lowest LC50 value of } \\
119.72 \mu \mathrm{g} / \mathrm{mL} \text {. SPPH by Alcalase were further separated } \\
\text { into four fractions }(>10,5-10,3-5 \text { and }<3 \mathrm{kDa}) \text {. } \\
\text { Fractions }<3 \mathrm{KDa} \text { showed the strongest antiproliferative } \\
\text { effects, which were } 43.87 \% \text { at } 100 \mu \mathrm{g} / \mathrm{mL}(p<0.05) \text {. The } \\
<3 \mathrm{kDa} \text { fractions could cause G2/M cell cycle arrest with } \\
\text { increased p } 21 \text { expression and induce apoptosis via } \\
\text { decreasing Bcl-2 expression, increasing Bax expression, } \\
\text { and inducing caspase- } 3 \text { activation in HT-29 cells. In } \\
\text { addition, }<3 \mathrm{kDa} \text { fractions could significantly inhibit the } \\
\text { cell migration of HT- } 29 \text { cells. }\end{array}$ & [173] \\
\hline
\end{tabular}

Regarding proteins, there are reports of silk proteins that are able to stabilize polar and non-polar antioxidants, due to the amphiphilic properties of fibroin. For example, Lou et al. (2016) used fibroin to stabilize vitamin C, curcumin, and epigallocatechin gallate. The results indicated that these antioxidants presented improved environmental stabilities of up to 14 days due to the binding of antioxidant molecules to the hydrophobic or the hydrophilic/hydrophilic boundary regions of silk [174]. Despite this work not being directly focused on CRC, it is highly relevant because antioxidants can easily react with air and other environmental conditions, losing their ROS -scavenging properties, prior to be 
consumed by the patient; without stabilization, the antioxidant simply will have little or no effect in the patient. Lerdchai et al. (2016) designed a mixture of Thai silk fibroin/gelatin (denaturalized protein) sponges for the dual controlled release of curcumin and docosahexaenoic acid for localized cancer treatment. The sponges were fabricated by freeze-drying and glutaraldehyde cross-linking techniques. The highly cross-linked and slowly degrading silk fibroin/gelatin (50/50) sponge released curcumin and/or DHA at the slowest rate (for 24 days). Sponges were not toxic to L929 mouse fibroblasts, but a ratio of 1:4 (curcumin/docosahexaenoic acid) had the highest inhibitory effect on the growth of cancer cells [175]. Finally, Lozano-Pérez et al. (2017) encapsulated quercetin in silk fibroin nanoparticles (175 nm diameter). The nanoparticles had a negative surface charge that allowed the sustained release of the antioxidant that occurred throughout the experiment in both phosphate buffer saline ( $\mathrm{pH} 7.4$ ) and simulated intestinal fluid ( $\mathrm{pH}$ 6.8) [176].

\subsubsection{Polyesters}

Polyesters are polymers that contain the ester functional group in their main chain [156]. Polyesters are produced via condensation or ring-opening reactions. Due to the strong presence of oxygen groups, this polymer can poses a negative charge that can respond to $\mathrm{pH}$ changes [177]. Moreover, some polyesters can be enzymatically degraded such as in the case of polycaprolactone (PCL), polylactic acid (PLA), and polyhydroxyalkanoates (PHA), among others [178-181]. Lipases are an important group of esterases for the biodegradation of aliphatic polyesters. They are produced in the pancreas, liver, and digestive system to break down fat [180]. Fat and polyesters have the same functional groups (esters), which leads the enzyme to degrade these polymers. For CRC, antioxidants have been successfully encapsulated in PLA and in Poly (DL-lactic-co-glycolic) acid (PLGA). PCL and PHA have been employed via mixtures and copolymers, as described in Section 6.4.9.

Alippilakkotte et al. (2018) encapsulated curcumin in polylactic acid (PLA) using an eco-friendly emulsification-solvent evaporation strategy. The method resulted in an efficiency of around $90 \%$. The in vitro release studies showed a sustained curcumin release, after a burst release, in the initial $12 \mathrm{~h}$. The curcumin-loaded PLA nanocapsules could easily penetrate into the cancer cells and can cause a sustained drug release for effective cancer treatment [177].

Pereira et al. (2018) encapsulated Guabiroba phenolic extract in Poly (DL-lactic-co-glycolic) acid (PLGA) nanoparticles to improve the stability, bioavailability, and bioactivity of the extract. The encapsulated extract proved to present a higher antioxidant capacity compared to free extract. Moreover, a reduction in ROS generation in non-cancer cells was achieved with lower extract concentrations $(p<0.05)$ after encapsulation [181].

\subsubsection{Poly(vinylpyrrolidones)}

Polyvinylpyrrolidone (PVP), commonly called polyvidone or povidone, is a water-soluble polymer made from the monomer $N$-vinylpyrrolidone by free-radical polymerization in the presence of AIBN as an initiator [182]. Dry PVP is a hygroscopic powder and readily absorbs up to $40 \%$ of water by its weight [182]. Nanofibers, particles, and films have been loaded with antioxidant extracts for drug delivery systems.

Sriyanti et al. (2017) and Andjani et al. (2017) developed electrospun nanofiber mats of polyvinyl(pyrrolidone) (PVP) with Garcinia mangostana extract (GME). The researchers found strong interactions of the PVP with the extract, which was molecularly dispersed in the electrospun PVP nanofiber matrix. The composite nanofiber mats exhibited very high antioxidant activities despite having been exposed to a high voltage during electrospinning [183,184]. A similar strategy was adopted by Andjani et al. (2017) and Zahra et al. (2019) using rotatory force spinning for encapsulating GME and Garlic (Allium sativum) extract; however, the obtained fibers were at the microscale [185,186].

Kamaruddin et al. (2018) developed sub-micron particles by the electrospraying of PVP and green tea extract. The researchers optimized the processes for obtaining the particles and saw the potential for drug delivery systems [186]. However, the particles were not tested for drug delivery applications 
for colorectal cancer. Similarly, Guamán-Balcázar et al. (2019) generated sub-micron particles of PVP with mango leaf extract, finding a relationship between the mango leaf extract/PVP ratio, temperature, and pressure of the supercritical antisolvent extraction process with the particle size (some of the particles were at the nanoscale). The in vitro desorption test showed a release profile of the extract components lasting up to $8 \mathrm{~h}$ under simulated intestinal fluids at $\mathrm{pH} 6.8$ [187].

Contardi et al. (2019) produced a new material of PVP plasticized with p-coumaric acid for the encapsulation of bioactive compounds of interest in the pharmaceutical industry. An initial model of the encapsulation of carminic acid was evaluated, finding that by varying the ratio of PVP to p-coumaric acid, the release profile can be adjusted from minutes to hours; for instance, a ratio of 2:1 (PVP/p-coumaric acid) has a release profile lasting up to $70 \mathrm{~h}$ to obtain $100 \%$ release [188].

\subsubsection{Composites, Copolymers, and Mixtures}

Composites and polymer mixtures take advantage of the synergystic effects of two polymers. For instance, one polymer may be highly compatible with the bioactive compound but not $\mathrm{pH}$ sensitive, thus the combination with another shell polymer will tailor the release profile. Some recent advances are presented below.

Thanyacharoen et al. (2018) developed a composite material of polyvinyl alcohol with chitosan to deliver gallic acid (antioxidant). The results seem promising as the gallic acid was released for periods longer than $16 \mathrm{~h}$ and its antioxidant properties were conserved [189].

Al-Ogaidi (2018) mixed two polysaccharides, alginate, and chitosan, to load vitamin C into nanoparticles of 25-30 nm in size. Moreover, Al-Ogaidi evaluated the effect of the $\mathrm{pH}$ on the overall size of the system, finding higher release at a $\mathrm{pH}$ of 6 . Furthermore, it was found that entrapping vitamin $C$ within the nanoparticle enhanced its anticancer activity [142]. Similar studies were carried out by Aluani et al. (2017) using quercetin instead of vitamin C [190]. Rahaiee et al. (2017) developed alginate-chitosan nanoparticles to stabilize crocin, an antioxidant with anticancer effects; crocin is highly sensitive to $\mathrm{pH}$, heat, and oxidative stress, making its effectiveness reduced. The alginate-chitosan nanoparticles showed a controlled release profile in simulated gastrointestinal fluids and effectively protected crocin from the environment prior to being released [191].

Huang et al. (2016) improved the water dispersibility of curcumin, using core-shell nanoparticles of zein (core) and alginate-pectin (shell). The researcher found that curcumin-loaded core-shell nanoparticles were shown to have superior antioxidant and radical scavenging activities compared to curcumin solubilized in ethanol [192]. Likewise, Wei et al. (2019) developed zein-propylene glycol alginate-rhamnolipid composite nanoparticles to overcome the limitations of resveratrol such as water insolubility and chemical instability; the nanoparticles controlled the release for up to $2 \mathrm{~h}$ [193].

Arunkumar created nanocapsules of $100 \mathrm{~nm}$ using poly (lactic-co-glycolic acid)-polyethylene glycol to improve the solubility and stability of lutein (an antioxidant with poor solubility). The capsules showed higher stability and improved the bioability of the lutein, enhancing the antiproliferative effect of the antioxidant, evidenced by the lower lethal concentration (LC50) of $10.9 \mu \mathrm{M}$ for the nanocapsules and $25 \mu \mathrm{M}$ for free lutein [194].

Jaiswal et al. (2019) synthesized methyl methacrylate (MMA)-modified chitosan (CS) by a green method via a Michael addition reaction between CS and MMA in ethanol. The nanoparticles of approximately $100 \mathrm{~nm}$ had, in an in vitro drug release study, a maximal curcumin entrapment efficiency up to $68 \%$ with a high release at a $\mathrm{pH}$ of 5.0 and a lower one at physiological $\mathrm{pH}$ [195]. Positive charges on chitosan will generate maximum delivery at acid $\mathrm{pH}$ (stomach) rather than neutral (colon). Consequently, this strategy is not recommended for CRC treatment, since curcumin would be delivered before arriving at the desired area.

Eatemadi et al. (2016) developed a nanoparticle of PCL-PEG-PCL to encapsulate chrysin (antioxidant). The researcher investigated the effect of chrysin-loaded PCL-PEG-PCL on the T47D breast cancer cell line. The cell viability assay showed that chrysin has a time-dependent cytotoxic effect on the T47D cell line. Furthermore, the conducted studies showed that encapsulated chrysin has 
a higher antitumor effect on the gene expression of FTO, BRCA1, and hTERT than free chrysin [196]. This study was not focused on CRC, but these systems can be easily extrapolated to gastrointestinal drug delivery.

Wu et al. (2016) evaluated the structural, mechanical, antioxidant, and cytocompatibility properties of membranes prepared from PHA and arrowroot (Maranta arundinacea) starch powder (ASP). Furthermore, the researchers grafted acrylic acid to PHA (PHA-g-AA). The PHA-g-AA/ASP membranes had better mechanical properties than the PHA/ASP membrane. This effect was attributed to greater compatibility between the grafted PHA and ASP. The water-resistance of the PHA-g-AA/ASP membranes was greater than that of the PHA/ASP membranes, and a cytocompatibility evaluation with human foreskin fibroblasts indicated that both materials were nontoxic. Moreover, ASP enhanced the polyphenol content and antioxidant properties when they were encapsulated [197].

\subsection{Polymers for Encapsulating Synthetics and Hybrid Adjuvants for CRC}

Synthetics and hybrid adjuvants are based on 5-FU. As explained previously, 5-FU is the gold standard for cancer and CRC adjuvant treatment. However, along with the growing interest in natural antioxidants, new hybrid compounds derived from 5-FU conjugated with natural or synthetic molecules have been developed; for example curcumin, has been conjugated with 5-FU to act synergistically by enhancing cellular uptake and accumulation, by inducing the destabilization of the cytoskeleton and loss of mitochondrial membrane potential, initiating early and late apoptosis in cancer cells [198]. Furthermore, synthetic drugs can be mixed with other natural or synthetic compounds to potentiate them or reduce the side effects. An example of this strategy is the mixing of 5-FU with resveratrol to reduce the toxicity of 5-FU against healthy cells [199]. Examples of other hybrids and mixtures were reviewed by Carrillo et al. (2015); the paper can be consulted in the following reference: [200].

The first attempts at looking at polymer encapsulation techniques for 5-FU and its derivatives are limited, mainly due to 5-FU being first patented in 1957 and then the research into encapsulating the molecule being governed by pharmaceutical companies. However, today, most of the patents have expired, making these compounds attractive for developing drug delivery systems. According to Scopus, there are more than 2800 documents related to 5-FU drug delivery systems. In 2018, more than 180 papers were published, and among them, 114 include the word "polymer". In the Table 4, some representative work from 2015 to 2019 is presented.

Table 4. Recent advances in using 5-fluorouracil (5-FU) and its derivatives in polymer encapsulation strategies for CRC.

\begin{tabular}{|c|c|c|c|}
\hline Compounds & Polymers & Highlights & References \\
\hline \multirow[t]{3}{*}{$\begin{array}{l}\text { 5-FU Mixed with } \\
\text { Doxorubicin (Dox) }\end{array}$} & $\begin{array}{l}\text { Dendritic nanomicelle of poly lactic } \\
\text { acid (core) and polyamidoamine } \\
\text { dendron (shell) }\end{array}$ & $\begin{array}{l}\text { The nanocapsule has a diameter of } 68.6 \pm 3.3 \\
\mathrm{~nm} \text { and shows a pH-sensitive drug release } \\
\text { behavior. The parallel activity of 5-FU and Dox } \\
\text { shows synergistic anticancer efficacy. }\end{array}$ & [201] \\
\hline & $\begin{array}{l}\text { Core-shell nanocapsules; core: } \\
\text { mesoporous silica; shell: } \\
\text { chitosan/PEG }\end{array}$ & $\begin{array}{l}\text { Drug loading ( } 0.15-0.18 \mathrm{mg} \text { of } 5 \mathrm{FU} / \mathrm{mg} \text { capsule). } \\
\text { Controlled release profiles }(15-65 \%) \text { over } 72 \mathrm{~h} . \\
\text { Cell specific cytotoxicity in cancer cells. }\end{array}$ & [202] \\
\hline & $\begin{array}{l}\text { Nanoparticles of PLGA conjugated } \\
\text { with folic acid }\end{array}$ & $\begin{array}{l}\text { Lower LC50 for encapsulated 5-FU against } \\
\text { HT-29 cancer cells compared with free 5-FU. } \\
\text { Folic acid on the surface of the nanoparticles } \\
\text { induces a rapid intake of the nanoparticle into } \\
\text { the cell. }\end{array}$ & [203] \\
\hline
\end{tabular}


Table 4. Cont.

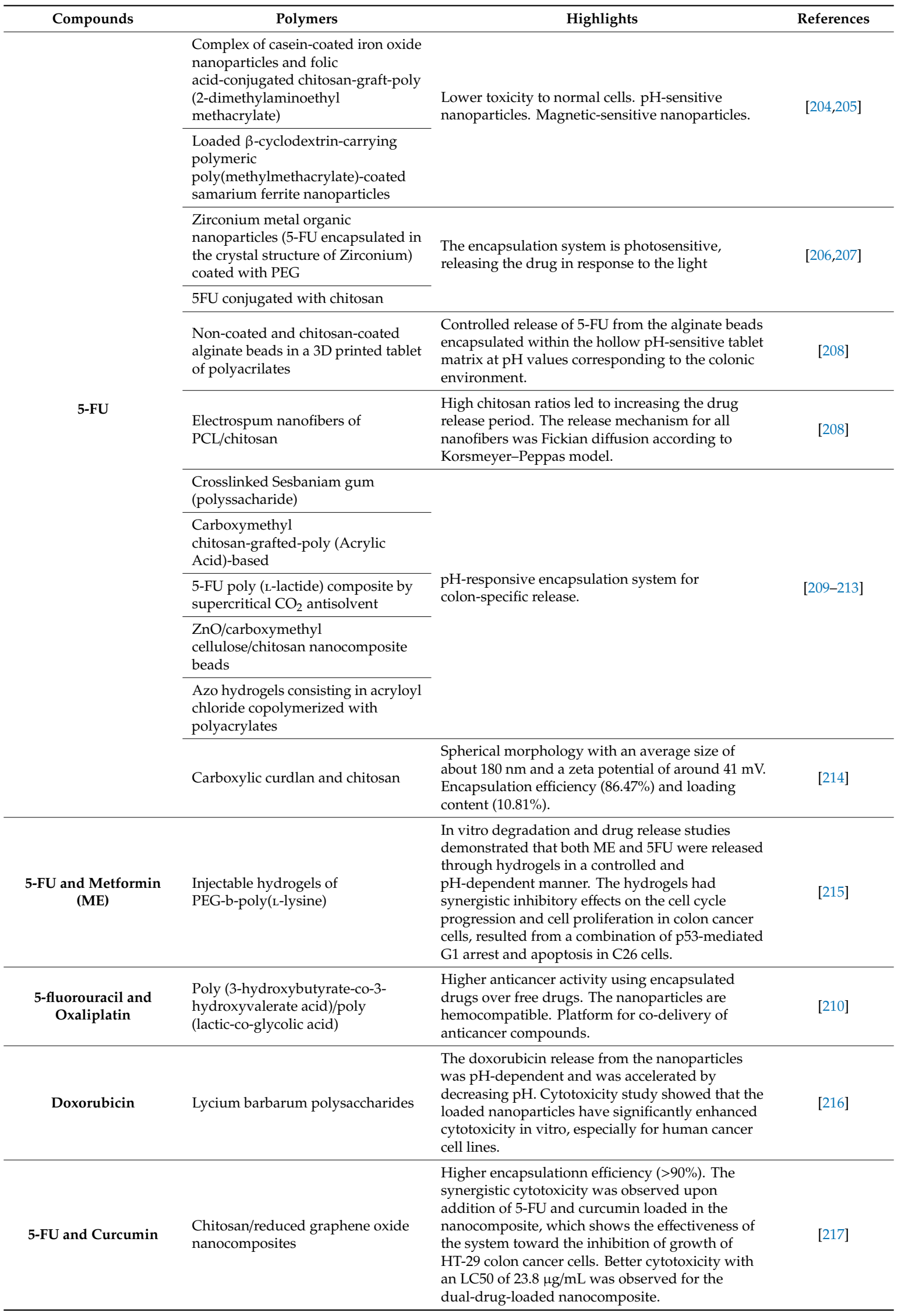


According to the above table, recent advances in synthetic adjuvants have been focused on improving the bioavailability of 5-FU. For example, for a $\mathrm{pH}$-sensitive polymer that will deliver the 5-FU in the colonic area, the modification of the polymer surface with folic acid makes it selective for receptors that are more active in cancer cells, for targeted therapy. Moreover, the blending of polymers and bioactive compounds is a new approach to reducing the toxic side effects of 5-FU and enhancing its therapeutic effects.

\section{Conclusions}

Actual cancer treatment is helping to increase the survival rates and prognosis and, in some cases, to cure cancer in patients. Nevertheless, the fight against cancer is not over, especially for CRC, which is one of the most aggressive cancer types. Consequently, cancer is and will remain a hot topic in research.

Among the different adjuvant therapies for complementing or avoiding the surgical removal of the affected area, oral chemotherapy is the most convenient for patients and health professionals. Chemotherapy treatment is continuously evolving to reduce side effects and enhance the therapeutic effects of natural and synthetics drugs, using strategies involving the encapsulation of bioactive compounds. Furthermore, thanks to molecular biology and chemistry, researchers can quickly check the anticancer properties of bioactive compounds in vitro and in vivo in order to compare treatments.

Polymers are versatile biomaterials that can be loaded with CRC-targeting compounds and processed to tailor the desorption kinetics to respond to $\mathrm{pH}$, enzymes, cellular receptors, and time, among others. Despite none of the studies aiming to compare response types $(\mathrm{pH}$, enzymes, time, or cellular receptors), $\mathrm{pH}$-responsive polymers are seemingly the most promising, so new research should be focused on studying polymer families with other ways of responding to stimuli. In vivo pharmacokinetics are a useful tool to compare polymers and bioactive compounds in order to optimize the therapeutic effects of such compounds.

Finally, it can be concluded that antioxidants are emerging compounds that, in the short term, will complement current chemotherapy treatments, and in the long term, these natural drugs will replace 5-FU and will play an important role in curing colorectal cancer.

Author Contributions: Conceptualization, M.O.; data acquisition, M.O.; writing-original draft preparation, M.O.; writing-review and editing, M.O., E.M., T.N. and C.C.; project administration, C.C.; All authors have read and agreed to the published version of the manuscript.

Funding: This research was funded by MINCIENCIAS, Colombia under the project Nanobiocáncer grand number FP44842-211-2018.

Acknowledgments: Authors wants to thanks to Ana Colorado from the VIGILA Department of the Universidad Pontificia Bolivariana for the valuable help in the use of Vantage, AcclaimIP and Derwent.

Conflicts of Interest: The authors declare no conflict of interest.

\section{References}

1. Roser, M.; Ritchie, H. Cancer. Available online: https://ourworldindata.org/cancer (accessed on 25 February 2019).

2. Becker, D.; Hershman, D.L. Adjuvant Therapy for Elderly Patients with Breast, Colon, and Lung Cancer. In Management of Cancer in the Older Patient; Elsevier: Philadelphia, PA, USA, 2012; pp. 79-88.

3. Institute for Health Metrics and Evaluation (IHME) Global Burden of Disease Collaborative Network. Available online: http://ghdx.healthdata.org/gbd-results-tool.\%0D\%0A (accessed on 25 February 2019).

4. Chiavarini, M.; Bertarelli, G.; Minelli, L.; Fabiani, R. Dietary intake of meat cooking-related mutagens (HCAs) and risk of colorectal adenoma and cancer: A systematic review and meta-analysis. Nutrients 2017, 9, 514. [CrossRef] [PubMed]

5. Romieu, I.; Bagnardi, V.; Scotti, L.; Negri, E.; La Vecchia, C.; Tramacere, I.; Rota, M.; Fedirko, V.; Straif, K.; Jenab, M.; et al. Alcohol drinking and colorectal cancer risk: An overall and dose-response meta-analysis of published studies. Ann. Oncol. 2011, 22, 1958-1972. [CrossRef] 
6. Lewis, R.; Burden, S. Colorectal cancer and nutrition. Adv. Nutr. Diet. Gastroenterol. 2014, 255-262. [CrossRef]

7. Ornitz, D.M.; Itoh, N. Protein family review Fibroblast growth factors Gene organization and evolutionary history. Genome Biol. 2001, 2, 1-12. [CrossRef] [PubMed]

8. Reyes-Aldasoro, C.C. The proportion of cancer-related entries in PubMed has increased considerably; Is cancer truly "the Emperor of All Maladies"? PLoS ONE 2017, 12, 1-15. [CrossRef]

9. Luke, M. Intestinal obstruction from cancer of the rectum, operation for artificial anus in the left groin; death in six hours. Lancet 1860, 6, 243. [CrossRef]

10. Dunphy, J.E. Recurrent Cancer of the Colon and Rectum. N. Engl. J. Med. 2010, 237, 1-3. [CrossRef]

11. Adams, J.T.; Schwartz, S.I.; Rubin, P.; Rob, C.G. Intralymphatic 5-Fluorouracil and radioactive gold as an adjuvant to surgical operation for colorectal carcinoma. Dis. Colon Rectum 1970, 13, 201-206. [CrossRef]

12. Grand View Research Vaccine Adjuvants Market sie and Analysis. Available online: https://www. grandviewresearch.com/industry-analysis/vaccine-adjuvants-market (accessed on 17 March 2019).

13. Gaudry, B.K.; Rothwell, R. The Unpredictable Prospects of Patenting Cancer Innovation. Available online: https://www.ipwatchdog.com/2018/03/01/unpredictable-patenting-cancer-innovation/id=94280/ (accessed on 17 March 2019).

14. Vainio, H.; Morgan, G. Aspirin for the second hundred years: New uses for an old drug. Pharmacol. Toxicol. 1997, 81, 151-152. [CrossRef]

15. X. Garcia-Albeniz, A.T.C. Aspirin for the prevention of colorectal cancer. Best Pr. Res Clin Gastroenterol. 2012, 1-18. [CrossRef]

16. Chan, A.T. Aspirin Use and Survival After Diagnosis of Colorectal Cancer. Jama 2009, 302, 649-659. [CrossRef] [PubMed]

17. Solomon, V.R.; Lee, H. Anti-breast cancer activity of heteroaryl chalcone derivatives. Biomed. Pharmacother. 2012, 66, 213-220. [CrossRef] [PubMed]

18. R. Solomon, V.; Lee, H. Quinoline as a Privileged Scaffold in Cancer Drug Discovery. Curr. Med. Chem. 2011, 18, 1488-1508. [CrossRef] [PubMed]

19. World Health Organization Cancer. Available online: https://www.who.int/cancer/en/ (accessed on 5 March 2019).

20. Hecker, E. Definitions and terminology in cancer (tumor) etiology. Bull. World Health Organ. 1976, 54, 463. [CrossRef]

21. National Institutes of Health (US); Biological Sciences Curriculum Study. Understanding Cancer. NIH Curric. Suppl. Ser. 2007.

22. Pelengaris, S.; Khan, M. The Molecular Biology of Cancer: A Bridge from Bench to Bedside, 2nd ed.; Pelengaris, S., Khan, M., Eds.; Wiley: West Sussex, UK, 2013; Volume 28.

23. NIH National Cancer Institutes Cancer Classification. Available online: https://training.seer.cancer.gov/ disease/categories/classification.html (accessed on 11 March 2019).

24. Gajdos, C.; Tartter, P.I.; Bodian, C.; Brower, S.T.; Bleiweiss, I.J. Stage 0 to stage III breast cancer in young women. J. Am. Coll. Surg. 2003, 190, 523-529. [CrossRef]

25. Edge, S.B.; Compton, C.C. The american joint committee on cancer: The 7th edition of the AJCC cancer staging manual and the future of TNM. Ann. Surg. Oncol. 2010, 17, 1471-1474. [CrossRef] [PubMed]

26. Idikio, H.A. Human cancer classification: A systems biology-based model integrating morphology, cancer stem cells, proteomics, and genomics. J. Cancer 2011, 2, 107-115. [CrossRef] [PubMed]

27. Ali, H.R.; Rueda, O.M.; Aparicio, S.A.; Caldas, C.; Dunning, M.J.; Curtis, C. Genome-driven integrated classification of breast cancer validated in over 7,500 samples. Genome Biol. 2014, 15, 1-14. [CrossRef]

28. Hoadley, K.A.; Yau, C.; Hinoue, T.; Wolf, D.M.; Lazar, A.J.; Drill, E.; Shen, R.; Taylor, A.M.; Cherniack, A.D.; Thorsson, V.S.; et al. Cell-of-Origin Patterns Dominate the Molecular Classification of 10,000 Tumors from 33 Types of Cancer. Cell 2018, 173, 291-304. [CrossRef]

29. Lee, Z.J. An integrated algorithm for gene selection and classification applied to microarray data of ovarian cancer. Artif. Intell. Med. 2008, 42, 81-93. [CrossRef] [PubMed]

30. Shen, L.; Toyota, M.; Kondo, Y.; Lin, E.; Zhang, L.; Guo, Y.; Hernandez, N.S.; Chen, X.; Ahmed, S.; Konishi, K.; et al. Integrated genetic and epigenetic analysis identifies three different subclasses of colon cancer. Proc. Natl. Acad. Sci. 2007, 104, 18654-18659. [CrossRef] [PubMed]

31. Bookshelf, N. Colorectal Cancer: Overview. Available online: https:/www.ncbi.nlm.nih.gov/books/ NBK279198/?report=printable (accessed on 13 March 2018). 
32. Cooper, G.M.; Hausman, R. The Cell: A Molecular Approach, 6th ed.; Cooper, G.M., Hausman, R., Eds.; ASM Press: Boston, MA, USA, 2013; ISBN 978-0878939640.

33. Jolly, T.A.; Williams, G.R.; Bushan, S.; Pergolotti, M.; Nyrop, K.A.; Jones, E.L.; Muss, H.B. Adjuvant treatment for older women with invasive breast cancer. Women's Heal. 2016, 12, 129-146. [CrossRef]

34. Ilson, D.H. Adjuvant therapy in colon cancer: Less is more. Lancet Oncol. 2018, 19, 442-443. [CrossRef]

35. Kazemi, T.; Younesi, V.; Jadidi-Niaragh, F.; Yousefi, M. Immunotherapeutic approaches for cancer therapy: An updated review. Artif. Cells, Nanomedicine Biotechnol. 2016, 44, 769-779. [CrossRef] [PubMed]

36. Kumari, S.; Badana, A.K.; Murali Mohan, G.; Shailender, G.; Malla, R.R. Reactive Oxygen Species: A Key Constituent in Cancer Survival. Biomark. Insights 2018, 13. [CrossRef]

37. Shi, J.; Fang, G.; Sheng, Y. Neo-adjuvant chemotherapy for breast cancer. Zhonghua Zhong Liu Za Zhi 2001, 23, 423-425. [CrossRef]

38. Jaffray, D.; Gospodarowicz, M. Radiation Therapy for Cancer. In Cancer: Disease Control Priorities; Gelband, H., Jha, P., Sankaranarayanan, R., Eds.; The International Bank for Reconstruction and Development: Washington, DC, USA, 2015; p. 10.

39. Häfner, M.F.; Debus, J. Radiotherapy for colorectal cancer: Current standards and future perspectives. Visc. Med. 2016, 32, 172-177. [CrossRef]

40. Skowronek, J. Current status of brachytherapy in cancer treatment-short overview. J. Contemp. Brachytherapy 2017, 9, 581-589. [CrossRef]

41. Johnson, J.R.; Lacey, J.V., Jr.; Lazovich, D.; Geller, M.A.; Schairer, C.; Schatzkin, A.; Flood, A. Menopausal Hormone Therapy and Risk of Colorectal Cancer. Cancer Epidemiol Biomarkers Prev. 2009, 18, 196-203. [CrossRef]

42. Lin, J.H.; Zhang, S.M.; Rexrode, K.M.; Manson, J.E.; Chan, A.T.; Wu, K.; Tworoger, S.S.; Hankinson, S.E.; Fuchs, C.; Gaziano, J.M.; et al. Association between sex hormones and colorectal cancer risk in men and women. Clin. Gastroenterol. Hepatol. 2014, 11, 419-424.e1. [CrossRef] [PubMed]

43. Rennert, G.; Rennert, H.S.; Pinchev, M.; Lavie, O.; Gruber, S.B. Use of hormone replacement therapy and the risk of colorectal cancer. J. Clin. Oncol. 2009, 27, 4542-4547. [CrossRef] [PubMed]

44. Venning, G.; Lange, S. Hormone Replacement Therapy. Available online: https://www.ncbi.nlm.nih.gov/ books/NBK493191/?report=printable (accessed on 2 July 2019).

45. Machluf, M.; Orsola, A.; Atala, A. Controlled release of therapeutic agents: Slow delivery and cell encapsulation. World J. Urol. 2000, 18, 80-83. [CrossRef]

46. Ohhara, Y.; Fukuda, N.; Takeuchi, S.; Honma, R.; Shimizu, Y.; Kinoshita, I.; Dosaka-Akita, H. Role of targeted therapy in metastatic colorectal cancer. World J. Gastrointest. Oncol. 2016, 8, 642. [CrossRef]

47. Hainsworth, J.; Heim, W.; Berlin, J.; Baron, A.; Griffing, S.; Holmgren, E.; Ph, D.; Ferrara, N.; Fyfe, G.; Rogers, B.; et al. Bevacizumab plus Irinotecan, Fluorouracil, and Leucovorin for Metastatic Colorectal Cancer. N. Engl. J. Med. 2004, 350, 2335-2342.

48. Longley, D.B.; Harkin, D.P.; Johnston, P.G. 5-Fluorouracil: Mechanisms of Action and Clinical Strategies. Nat. Rev. Cancer 2003, 3, 330-338. [CrossRef]

49. Zouhairi, M.E.; Charabaty, A.; Pishvaian, M.J. Molecularly targeted therapy for metastatic colon cancer: Proven treatments and promising new agents. Gastrointest. Cancer Res. 2011, 4, 15-21.

50. Pitt, J.M.; Kroemer, G.; Zitvogel, L.; Pitt, J.M.; André, F.; Amigorena, S.; Soria, J.; Eggermont, A. Dendritic cell-derived exosomes for cancer therapy Find the latest version: Dendritic cell-derived exosomes for cancer therapy. J. Clin. Investig. 2016, 126, 1224-1232. [CrossRef]

51. Adams, G.P.; Weiner, L.M. Monoclonal antibody therapy of cancer. Nat. Biotechnol. 2005, 23, 1147-1157. [CrossRef]

52. Anderson, R.J.; Schneider, J. Plasmid DNA and viral vector-based vaccines for the treatment of cancer. Vaccine 2007, 25, 24-34. [CrossRef]

53. Diakos, C.I.; Charles, K.A.; McMillan, D.C.; Clarke, S.J. Cancer-related inflammation and treatment effectiveness. Lancet Oncol. 2014, 15, e493-e503. [CrossRef]

54. Lianos, G.D.; Alexiou, G.A.; Mangano, A.; Mangano, A.; Rausei, S.; Boni, L.; Dionigi, G.; Roukos, D.H. The role of heat shock proteins in cancer. Cancer Lett. 2015, 360, 114-118. [CrossRef] [PubMed]

55. Institue for Quality and Efficiency in Health Care How Does Chemotherapy Work? Available online: http://www.ncbi.nlm.nih.gov/pubmedhealth/PMH0041062/ (accessed on 2 July 2019). 
56. Gustavsson, B.; Carlsson, G.; MacHover, D.; Petrelli, N.; Roth, A.; Schmoll, H.J.; Tveit, K.M.; Gibson, F. A review of the evolution of systemic chemotherapy in the management of colorectal cancer. Clin. Colorectal Cancer 2015, 14, 1-10. [CrossRef] [PubMed]

57. Petrelli, N.; Herrera, L.; Rustum, Y.; Burke, P.; Creaven, P.; Stulc, J.; Emrich, L.J.; Mittelman, A. A prospective randomized trial of 5-fluorouracil versus 5-fluorouracil and high-dose leucovorin versus 5-fluorouracil and methotrexate in previously untreated patients with advanced colorectal carcinoma. J. Clin. Oncol. 1987, 5, 1559-1565. [CrossRef]

58. Goldberg, R.M.; Sargent, D.J.; Morton, R.F.; Fuchs, C.S.; Ramanathan, R.K.; Williamson, S.K.; Findlay, B.P.; Pitot, H.C.; Alberts, S.R. A Randomized Controlled Trial of Fluorouracil Plus Leucovorin, Irinotecan, and Oxaliplatin Combinations in Patients With Previously Untreated Metastatic Colorectal Cancer. J. Clin. Oncol. 2004, 22, 23-30. [CrossRef]

59. Tveit, K.M.; Guren, T.; Glimelius, B.; Pfeiffer, P.; Sorbye, H.; Pyrhonen, S.; Sigurdsson, F.; Kure, E.; Ikdahl, T.; Skovlund, E.; et al. Phase III Trial of Cetuximab With Continuous or Intermittent Fluorouracil, Leucovorin, and Oxaliplatin (Nordic FLOX) Versus FLOX Alone in First-Line Treatment of Metastatic Colorectal Cancer: The NORDIC-VII Study. J. Clin. Oncol. 2012, 30, 1755-1762. [CrossRef]

60. Yokoyama, C.; Sueyoshi, Y.; Ema, M.; Mori, Y.; Takaishi, K.; Hisatomi, H. Induction of oxidative stress by anticancer drugs in the presence and absence of cells. Oncol. Lett. 2017, 14, 6066-6070. [CrossRef]

61. Abbas, M.; Saeed, F.; Anjum, F.M.; Afzaal, M.; Tufail, T.; Bashir, M.S.; Ishtiaq, A.; Hussain, S.; Suleria, H.A.R. Natural polyphenols: An overview. Int. J. Food Prop. 2017, 20, 1689-1699. [CrossRef]

62. Jin, X.; Che, D.B.; Zhang, Z.H.; Yan, H.M.; Jia, Z.Y.; Jia, X. Bin Ginseng consumption and risk of cancer: A meta-analysis. J. Ginseng Res. 2016, 40, 269-277. [CrossRef]

63. Wong, A.S.T.; Cheb, C.-M.; Leunga, K.-W. Ginseng as cancer therapeutics: Recent advances in functional and mechanistic overview. Nat. Prod. Rep. 2015. [CrossRef]

64. Chong-zhi, W.; Anderson, S.; Wei, D.U.; Tong-chuan, H.E.; Chun-su, Y. Red ginseng and cancer treatment. Chin. J. Nat. Med. 2016, 14, 7-16. [CrossRef]

65. Tang, Y.C.; Zhang, Y.; Zhou, J.; Zhi, Q.; Wu, M.Y.; Gong, F.R.; Shen, M.; Liu, L.; Tao, M.; Shen, B.; et al. Ginsenoside Rg3 targets cancer stem cells and tumor angiogenesis to inhibit colorectal cancer progression in vivo. Int. J. Oncol. 2018, 52, 127-138. [CrossRef]

66. Kim, E.J.; Kwon, K.A.; Lee, Y.E.; Kim, J.H.; Kim, S.H.; Kim, J.H. Korean Red Ginseng extract reduces hypoxia-induced epithelial-mesenchymal transition by repressing NF- $\mathrm{kB}$ and ERK1/2 pathways in colon cancer. J. Ginseng Res. 2018, 42, 288-297. [CrossRef] [PubMed]

67. Girisa, S.; Shabnam, B.; Monisha, J.; Fan, L.; Halim, C.E.; Arfuso, F.; Ahn, K.S.; Sethi, G.; Kunnumakkara, A.B. Potential of zerumbone as an anti-cancer agent. Molecules 2019, 24, 734. [CrossRef] [PubMed]

68. Sithara, T.; Dhanya, B.P.; Arun, K.B.; Sini, S.; Dan, M.; Kokkuvayil Vasu, R.; Nisha, P. Zerumbone, a Cyclic Sesquiterpene from Zingiber zerumbet Induces Apoptosis, Cell Cycle Arrest, and Antimigratory Effects in SW480 Colorectal Cancer Cells. J. Agric. Food Chem. 2018, 66, 602-612. [CrossRef] [PubMed]

69. Kim, H.J.; Kang, S.; Kim, D.Y.; You, S.; Park, D.; Oh, S.C.; Lee, D.H. Diallyl disulfide (DADS) boosts TRAIL-Mediated apoptosis in colorectal cancer cells by inhibiting Bcl-2. Food Chem. Toxicol. 2019, 125, 354-360. [CrossRef]

70. Roy, N.; Nazeem, P.A.; Babu, T.D.; Abida, P.S.; Narayanankutty, A.; Valsalan, R.; Valsala, P.A.; Raghavamenon, A.C. EGFR gene regulation in colorectal cancer cells by garlic phytocompounds with special emphasis on S-Allyl-L-Cysteine Sulfoxide. Interdiscip. Sci. Comput. Life Sci. 2018, 10, 686-693. [CrossRef]

71. Li, H.Y.; Li, M.; Luo, C.C.; Wang, J.Q.; Zheng, N. Lactoferrin Exerts Antitumor Effects by Inhibiting Angiogenesis in a HT29 Human Colon Tumor Model. J. Agric. Food Chem. 2017, 65, 10464-10472. [CrossRef]

72. Sugihara, Y.; Zuo, X.; Takata, T.; Jin, S.; Miyauti, M.; Isikado, A.; Imanaka, H.; Tatsuka, M.; Qi, G.; Shimamoto, F. Inhibition of DMH-DSS-induced colorectal cancer by liposomal bovine lactoferrin in rats. Oncol. Lett. 2017, 14, 5688-5694. [CrossRef]

73. Yang, C.S.; Wang, H. Cancer preventive activities of tea catechins. Molecules 2016, 21, 1679. [CrossRef]

74. Gómez-Juaristi, M.; Martínez-López, S.; Sarria, B.; Bravo, L.; Mateos, R. Absorption and metabolism of yerba mate phenolic compounds in humans. Food Chem. 2018, 240, 1028-1038. [CrossRef] [PubMed] 
75. Amigo-Benavent, M.; Wang, S.; Mateos, R.; Sarriá, B.; Bravo, L. Antiproliferative and cytotoxic effects of green coffee and yerba mate extracts, their main hydroxycinnamic acids, methylxanthine and metabolites in different human cell lines. Food Chem. Toxicol. 2017, 106, 125-138. [CrossRef] [PubMed]

76. Schmit, S.L.; Rennert, H.S.; Rennert, G.; Gruber, S.B. Coffee consumption and the risk of colorectal cancer. Cancer Epidemiol. Biomarkers Prev. 2016, 25, 634-639. [CrossRef]

77. Scafuri, B.; Marabotti, A.; Carbone, V.; Minasi, P.; Dotolo, S.; Facchiano, A. A theoretical study on predicted protein targets of apple polyphenols and possible mechanisms of chemoprevention in colorectal cancer. Sci. Rep. 2016, 6, 1-13. [CrossRef] [PubMed]

78. Darband, S.G.; Kaviani, M.; Yousefi, B.; Sadighparvar, S.; Pakdel, F.G.; Attari, J.A.; Mohebbi, I.; Naderi, S.; Majidinia, M. Quercetin: A functional dietary flavonoid with potential chemo-preventive properties in colorectal cancer. J. Cell. Physiol. 2018, 233, 6544-6560. [CrossRef] [PubMed]

79. Huang, Y.-F.; Zhu, D.-J.; Chen, X.-W.; Chen, Q.-K.; Luo, Z.-T.; Liu, C.-C.; Wang, G.-X.; Zhang, W.-J.; Liao, N.-Z. Curcumin enhances the effects of irinotecan on colorectal cancer cells through the generation of reactive oxygen species and activation of the endoplasmic reticulum stress pathway. Oncotarget 2017, 8, 40264-40275. [CrossRef] [PubMed]

80. Ravindranathan, P.; Pasham, D.; Balaji, U.; Cardenas, J.; Gu, J.; Toden, S.; Goel, A. A combination of curcumin and oligomeric proanthocyanidins offer superior anti-tumorigenic properties in colorectal cancer. Sci. Rep. 2018, 8, 1-12. [CrossRef]

81. Marjaneh, R.M.; Rahmani, F.; Hassanian, S.M.; Rezaei, N.; Hashemzehi, M.; Bahrami, A.; Ariakia, F.; Fiuji, H.; Sahebkar, A.; Avan, A.; et al. Phytosomal curcumin inhibits tumor growth in colitis-associated colorectal cancer. J. Cell. Physiol. 2018, 233, 6785-6798. [CrossRef]

82. Carlos, D.A.; Sandra, A.; Fabián, C.-M.; Benjamín, R.; Maria, E.M. Antiproliferative and pro-apoptotic effects of Andean berry juice (Vaccinium meridionale Swartz) on human colon adenocarcinoma SW480 cells. J. Med. Plants Res. 2017, 11, 393-402. [CrossRef]

83. Buhrmann, C.; Yazdi, M.; Popper, B.; Shayan, P.; Goel, A.; Aggarwal, B.B.; Shakibaei, M. Resveratrol chemosensitizes TNF- $\beta$-induced survival of 5-FU-treated colorectal cancer cells. Nutrients 2018, 10, 888. [CrossRef]

84. Buhrmann, C.; Yazdi, M.; Popper, B.; Shayan, P.; Goel, A.; Aggarwal, B.B.; Shakibaei, M. Evidence that TNF- $\beta$ induces proliferation in colorectal cancer cells and resveratrol can down-modulate it. Exp. Biol. Med. 2019, 244, 1-12. [CrossRef] [PubMed]

85. Chang, C.Y.; Ho, B.Y.; Pan, T.M. Lactobacillus paracasei subsp. paracasei NTU 101-fermented skim milk as an adjuvant to uracil-tegafur reduces tumor growth and improves chemotherapy side effects in an orthotopic mouse model of colorectal cancer. J. Funct. Foods 2019, 55, 36-47. [CrossRef]

86. Turan, I.; Demir, S.; Kilinc, K.; Yaman, S.O.; Misir, S.; Kara, H.; Genc, B.; Mentese, A.; Aliyazicioglu, Y.; Deger, O. Cytotoxic effect of Rosa canina extract on human colon cancer cells through repression of telomerase expression. J. Pharm. Anal. 2018, 8, 394-399. [CrossRef] [PubMed]

87. Aguilera, O.; Muñoz-Sagastibelza, M.; Torrejón, B.; Borrero-Palacios, A.; del Puerto-Nevado, L.; Martínez-Useros, J.; Rodriguez-Remirez, M.; Zazo, S.; García, E.; Fraga, M.; et al. Vitamin C uncouples the Warburg metabolic switch in KRAS mutant colon cancer. Oncotarget 2016, 7. [CrossRef]

88. Semeraro, P.; Chimienti, G.; Altamura, E.; Fini, P.; Rizzi, V.; Cosma, P. Chlorophyll a in cyclodextrin supramolecular complexes as a natural photosensitizer for photodynamic therapy (PDT) applications. Mater. Sci. Eng. C 2018, 85, 47-56. [CrossRef]

89. Bantal, V.; Ghanta, P.; Tejasvi, P. Piperine Presents Chemo-preventive Property Against 1, 2-Dimethyl Hydrazine Induced Colon Cancer in Mice: Biochemical and Physiological Evidences. Pharmacologia 2018. [CrossRef]

90. Tan, B.L.; Norhaizan, M.E. Manilkara zapota (L.) P. Royen leaf water extract triggered apoptosis and activated caspase-dependent pathway in HT-29 human colorectal cancer cell line. Biomed. Pharmacother. 2019, 110, 748-757. [CrossRef]

91. Brglez Mojzer, E.; Knez Hrnčič, M.; Škerget, M.; Knez, Ž.; Bren, U. Polyphenols: Extraction Methods, Antioxidative Action, Bioavailability and Anticarcinogenic Effects. Molecules 2016, 21, 901. [CrossRef]

92. Bamia, C.; Lagiou, P.; Buckland, G.; Grioni, S.; Agnoli, C.; Taylor, A.J.; Dahm, C.C.; Overvad, K.; Olsen, A.; Tjønneland, A.; et al. Mediterranean diet and colorectal cancer risk: Results from a European cohort. Eur. J. Epidemiol. 2013, 28, 317-328. [CrossRef] 
93. Tibbitt, M.W.; Dahlman, J.E.; Langer, R. Emerging Frontiers in Drug Delivery. J. Am. Chem. Soc. 2016, 138, 704-717. [CrossRef]

94. Ferreira, I.; Rocha, S.; Coelho, M. Encapsulation of Antioxidants by Spray-Drying. Mater. Eng. 2005, 11, 713-717.

95. Kothamasu, P.; Kanumur, H.; Ravur, N.; Maddu, C.; Parasuramrajam, R.; Thangavel, S. Nanocapsules: The weapons for novel drug delivery systems. BioImpacts 2012, 2, 71-81. [CrossRef] [PubMed]

96. Contreras-Cáceres, R.; Cabeza, L.; Perazzoli, G.; Díaz, A.; López-Romero, J.M.; Melguizo, C.; Prados, J. Electrospun Nanofibers: Recent Applications in Drug Delivery and Cancer Therapy. Nanomaterials 2019, 9, 656. [CrossRef] [PubMed]

97. Suganya, V.; Anuradha, V. Microencapsulation and Nanoencapsulation: A Review. Int. J. Pharm. Clin. Res. 2017, 9, 233-239. [CrossRef]

98. Trucillo, P.; Campardelli, R.; Reverchon, E. Production of liposomes loaded with antioxidants using a supercritical $\mathrm{CO}_{2}$ assisted process. Powder Technol. 2018, 323, 155-162. [CrossRef]

99. Paini, M.; Daly, S.R.; Aliakbarian, B.; Fathi, A.; Tehrany, E.A.; Perego, P.; Dehghani, F.; Valtchev, P. An efficient liposome based method for antioxidants encapsulation. Colloids Surfaces B Biointerfaces 2015, 136, 1067-1072. [CrossRef]

100. Li, Q.; Cai, T.; Huang, Y.; Xia, X.; Cole, S.P.C.; Cai, Y. A review of the structure, preparation, and application of NLCs, PNPs, and PLNs. Nanomaterials 2017, 7, 122. [CrossRef]

101. Thakur, R.P.; Rai, K.N. Advances and Implications in Nanotechnology for Lung Cancer Management. Curr. drug Metab. 2017, 18. [CrossRef]

102. Bazylińska, U.; Wawrzyńczyk, D.; Kulbacka, J.; Fraçkowiak, R.; Cichy, B.; Bednarkiewicz, A.; Samoć, M.; Wilk, K.A. Polymeric nanocapsules with up-converting nanocrystals cargo make ideal fluorescent bioprobes. Sci. Rep. 2016, 6. [CrossRef]

103. Ibrahim, M.M.; El-Zawawy, W.K.; Nassar, M.A. Synthesis and characterization of polyvinyl alcohol/nanospherical cellulose particle films. Carbohydr. Polym. 2010, 79, 694-699. [CrossRef]

104. Hirai, A.; Inui, O.; Horii, F.; Tsuji, M. Phase separation behavior in aqueous suspensions of bacterial cellulose nanocrystals prepared by sulfuric acid treatment. Langmuir 2009, 25, 497-502. [CrossRef] [PubMed]

105. Franco, R.A.; Nguyen, T.H.; Lee, B.T. Electro-spinning of PLGA/PCL blends for tissue engineering and their biocompatibility. J. Mater. Sci. Mater. Med. 2011, 22, 2207-2218. [CrossRef] [PubMed]

106. Asabuwa Ngwabebhoh, F.; Ilkar Erdagi, S.; Yildiz, U. Pickering emulsions stabilized nanocellulosic-based nanoparticles for coumarin and curcumin nanoencapsulations: In vitro release, anticancer and antimicrobial activities. Carbohydr. Polym. 2018, 201,317-328. [CrossRef] [PubMed]

107. Choi, J.Y.; Gupta, B.; Ramasamy, T.; Jeong, J.H.; Jin, S.G.; Choi, H.G.; Yong, C.S.; Kim, J.O. PEGylated polyaminoacid-capped mesoporous silica nanoparticles for mitochondria-targeted delivery of celastrol in solid tumors. Colloids Surfaces B Biointerfaces 2018, 165, 56-66. [CrossRef] [PubMed]

108. Anandharamakrishnan, C. Techniques for Nanoencapsulation of Food Ingredients, 1st ed.; Anandharamakrishnan, C., Ed.; Springer: Madison, WI, USA, 2014.

109. Siepmann, J.; Peppas, N.A. Modeling of drug release from delivery systems based on hydroxypropyl methylcellulose (HPMC). Adv. Drug Deliv. Rev. 2001, 48, 139-157. [CrossRef]

110. Fenton, O.S.; Olafson, K.N.; Pillai, P.S.; Mitchell, M.J.; Langer, R. Advances in Biomaterials for Drug Delivery. Adv. Mater. 2018, 30, 1-29. [CrossRef]

111. Montagne, L.; Pluske, J.; Hampson, D. A review of interactions between dietary fibre and the intestinal mucosa, and their consequences on digestive health in young non-ruminant animals. Anim. Feed Sci. Technol. 2003, 108, 95-117. [CrossRef]

112. Tian, Z.; Yu, Q.; Xie, Y.; Li, F.; Lu, Y.; Dong, X.; Zhao, W.; Qi, J.; Wu, W. Controlling Release of Integral Lipid Nanoparticles Based on Osmotic Pump Technology. Pharm. Res. 2016, 33, 1988-1997. [CrossRef]

113. Quideau, S.; Deffieux, D.; Douat-Casassus, C.; Pouységu, L. Plant polyphenols: Chemical properties, biological activities, and synthesis. Angew. Chemie - Int. Ed. 2011, 50, 586-621. [CrossRef]

114. Kiokias, S.; Proestos, C.; Varzakas, T. A Review of the Structure, Biosynthesis, Absorption of Carotenoids-Analysis and Properties of their Common Natural Extracts. Curr. Res. Nutr. Food Sci. J. 2016, 4, 25-37. [CrossRef]

115. Liyana-Pathirana, C.M.; Shahidi, F. Antioxidant activity of commercial soft and hard wheat (Triticum aestivum L.) as affected by gastric pH conditions. J. Agric. Food Chem. 2005, 53, 2433-2440. [CrossRef] 
116. Pettinato, M.; Aliakbarian, B.; Casazza, A.A.; Perego, P. Encapsulation of Antioxidants from Spent Coffee Ground Extracts by Spray Drying. Chem. Eng. Trans. 2017, 57, 1219-1224. [CrossRef]

117. Yoon, S.H.; Jin, H.-J.; Kook, M.-C.; Pyun, Y.R. Electrically conductive bacterial cellulose by incorporation of carbon nanotubes. Biomacromolecules 2006, 7, 1280-1284. [CrossRef] [PubMed]

118. McMurry, J. Quimica Organica, 6th ed.; Thomson: Mexico City, Mexico, 2004; ISBN 9706863545.

119. Kyatanwar, A.U. Self micro-emulsifying drug delivery system (SMEDDS): Review. J. Pharm. Res. 2010,7 , 9. [CrossRef]

120. Shrestha, H.; Bala, R.; Arora, S. Lipid-Based Drug Delivery Systems. J. Pharm. 2014, 2014, 1-10. [CrossRef]

121. García-Pinel, B.; Porras-Alcalá, C.; Ortega-Rodríguez, A.; Sarabia, F.; Prados, J.; Melguizo, C.; López-Romero, J.M. Lipid-Based Nanoparticles: Application and Recent Advances in Cancer Treatment. Nanomaterials 2019, 9, 638. [CrossRef] [PubMed]

122. Aisner, J. Overview of the changing paradigm in cancer treatment: Oral chemotherapy. Am. J. Heal. Pharm. 2007, 64, 4-7. [CrossRef]

123. Kerz, T.; Paret, G.; Herff, H. Routes of drug administration. Int. J. Pharm. Stud. Res. 2007, I, 614-638. [CrossRef]

124. Osorio-Delgado, M.A.; Henao-Tamayo, L.J.; Velásquez-Cock, J.A.; Cañas-Gutierrez, A.I.; Restrepo-Múnera, L.M.; Gañán-Rojo, P.F.; Zuluaga-Gallego, R.O.; Ortiz-Trujillo, I.C.; Castro-Herazo, C.I. Biomedical applications of polymeric biomaterials. DYNA 2017, 84. [CrossRef]

125. Han, U.; Seo, Y.; Hong, J. Effect of $\mathrm{pH}$ on the structure and drug release profiles of layer-by-layer assembled films containing polyelectrolyte, micelles, and graphene oxide. Sci. Rep. 2016, 6, 1-10. [CrossRef]

126. Guarino, V.; Causa, F.; Taddei, P.; di Foggia, M.; Ciapetti, G.; Martini, D.; Fagnano, C.; Baldini, N.; Ambrosio, L. Polylactic acid fibre-reinforced polycaprolactone scaffolds for bone tissue engineering. Biomaterials 2008, 29, 3662-3670. [CrossRef]

127. Mathew, A.P.; Oksman, K.; Pierron, D.; Harmad, M.F. Crosslinked fibrous composites based on cellulose nanofibers and collagen with in situ $\mathrm{pH}$ induced fibrillation. Cellulose 2012, 19, 139-150. [CrossRef]

128. Mérillon, K.G.; RamawatJ, J.-M. Polysaccharides: Bioactivity and Biotechnology, 1st ed.; Mérillon, K.G., RamawatJ, J.-M., Eds.; Springer: Zug, Switzerland, 2015; ISBN 978-3-319-16297-3.

129. Kosaraju, S.L. Colon targeted delivery systems: Review of polysaccharides for encapsulation and delivery. Crit. Rev. Food Sci. Nutr. 2005, 45, 251-258. [CrossRef]

130. Osorio, M.A.; Restrepo, D.; Velásquez-Cock, J.A.; Zuluaga, R.O.; Montoya, U.; Rojas, O.; Gañán, P.F.; Marin, D.; Castro, C.I. Synthesis of thermoplastic starch-bacterial cellulose nanocomposites via in situ fermentation. J. Braz. Chem. Soc. 2014, 25. [CrossRef]

131. Velásquez-Cock, J.; Castro, C.; Gañán, P.; Osorio, M.; Putaux, J.L.; Serpa, A.; Zuluaga, R. Influence of the maturation time on the physico-chemical properties of nanocellulose and associated constituents isolated from pseudostems of banana plant c.v. Valery. Ind. Crops Prod. 2016, 83, 551-560. [CrossRef]

132. Sunasee, R.; Despres, H.W.; Nunez, K.D.; Ckless, K.; Pacherille, A.; Carson, M. Analysis of the Immune and Antioxidant Response of Cellulose Nanocrystals Grafted with $\beta$-Cyclodextrin in Myeloid Cell Lines. J. Nanomater. 2019, 2019, 1-9. [CrossRef]

133. Li, X.; Liu, Y.; Yu, Y.; Chen, W.; Liu, Y.; Yu, H. Nanoformulations of quercetin and cellulose nanofibers as healthcare supplements with sustained antioxidant activity. Carbohydr. Polym. 2019, 207, 160-168. [CrossRef]

134. Ching, Y.C.; Gunathilake, T.M.S.U.; Chuah, C.H.; Ching, K.Y.; Singh, R.; Liou, N.S. Curcumin/Tween 20-incorporated cellulose nanoparticles with enhanced curcumin solubility for nano-drug delivery: Characterization and in vitro evaluation. Cellulose 2019, 26, 5467-5481. [CrossRef]

135. Elieh-Ali-Komi, D.; Hamblin, M.R. Chitin and Chitosan: Production and Application of Versatile Biomedical Nanomaterials. Int. J. Adv. Res. 2016, 4, 411-427. [CrossRef]

136. Kumar, S.P.; Birundha, K.; Kaveri, K.; Devi, K.T.R. Antioxidant studies of chitosan nanoparticles containing naringenin and their cytotoxicity effects in lung cancer cells. Int. J. Biol. Macromol. 2015, 78, 87-95. [CrossRef]

137. Jeong, H.; Samdani, K.J.; Yoo, D.H.; Lee, D.W.; Kim, N.H.; Yoo, I.S.; Lee, J.H. Resveratrol cross-linked chitosan loaded with phospholipid for controlled release and antioxidant activity. Int. J. Biol. Macromol. 2016, 93, 757-766. [CrossRef] [PubMed]

138. Shi, M.; Bai, J.; Zhao, L.; Yu, X.; Liang, J.; Liu, Y.; Nord, W.; Li, Y. Co-loading and intestine-specific delivery of multiple antioxidants in $\mathrm{pH}$-responsive microspheres based on TEMPO-oxidized polysaccharides. Carbohydr. Polym. 2017, 157, 858-865. [CrossRef] 
139. Sookkasem, A.; Chatpun, S.; Yuenyongsawad, S.; Wiwattanapatapee, R. Alginate beads for colon specific delivery of self-emulsifying curcumin. J. Drug Deliv. Sci. Technol. 2015, 29, 159-166. [CrossRef]

140. Wang, H.; Gong, X.; Guo, X.; Liu, C.; Fan, Y.Y.; Zhang, J.; Niu, B.; Li, W. Characterization, release, and antioxidant activity of curcumin-loaded sodium alginate/ZnO hydrogel beads. Int. J. Biol. Macromol. 2019, 121, 1118-1125. [CrossRef]

141. Elgegren, M.; Kim, S.; Cordova, D.; Silva, C.; Noro, J.; Cavaco-paulo, A.; Nakamatsu, J. Ultrasound-Assisted Encapsulation of Sacha Inchi (Plukenetia volubilis Linneo.) Oil in Alginate-Chitosan Nanoparticles Mariela. Polymers (Basel). 2019, 11, 1245. [CrossRef]

142. Al-Ogaidi, I. Evaluation of the Antioxidant and Anticancer Effects of Biodegradable / Biocompatible Chitosan - Alginate Nanoparticles Loaded with. Int. J. Pharm. Res. Allied Sci. 2018, 7, 189-197.

143. Min, J.-Y.; Ahn, S.-I.; Lee, Y.-K.; Kwak, H.-S.; Chang, Y.H. Optimized conditions to produce water-in-oil-in-water nanoemulsion and spray-dried nanocapsule of red ginseng extract. Food Sci. Technol. 2018, 38, 485-492. [CrossRef]

144. Pan, K.; Chen, H.; Seung Joon, B.; Zhong, Q. Self-assembled curcumin-soluble soybean polysaccharide nanoparticles: Physicochemical properties and in vitro anti- proliferation activity against cancer cells Kang. Food Chem. 2019, 344, 1173-1178. [CrossRef]

145. Li, X.; Li, M.; Liu, J.; Ji, N.; Liang, C.; Sun, Q.; Xiong, L. Preparation of hollow biopolymer nanospheres employing starch nanoparticle templates for enhancement of phenolic acid antioxidant activities. J. Agric. Food Chem 2017, 48. [CrossRef]

146. Assis, R.Q.; Lopes, S.M.; Costa, T.M.H.; Flôres, S.H.; Rios, A.d.O. Active biodegradable cassava starch films incorporated lycopene nanocapsules. Ind. Crops Prod. 2017, 109, 818-827. [CrossRef]

147. Ahmad, M.; Mudgil, P.; Gani, A.; Hamed, F.; Masoodi, F.A.; Maqsood, S. Nano-encapsulation of catechin in starch nanoparticles: Characterization, release behavior and bioactivity retention during simulated in-vitro digestion. Food Chem. 2019, 270, 95-104. [CrossRef]

148. Jana, S.; Maiti, S.; Jana, S. Stimuli-responsive guar gum composites for colon-specific drug delivery. In Biopolymer-Based Composites: Drug Delivery and Biomedical Applications; Sougata, J., Sabyasachi, M., Subrata, J., Eds.; Elsevier Ltd: Cambridge, MA, USA, 2017; pp. 61-79. ISBN 9780081019153.

149. Saffarzadeh-Matin, S.; Shahbazi, M. Maltodextrine nanoparticles loaded with polyphenolic extract from apple industrial waste:Preparation, optimization and characterization. RSM Optim. S. Saffarzadeh-Matin al. / J. Part. Sci. Technol. 2017, 3, 197-209. [CrossRef]

150. Garay-Jimenez, J.C.; Turos, E. A convenient method to prepare emulsified polyacrylate nanoparticles from for drug delivery applications. Bioorganic Med. Chem. Lett. 2011, 21, 4589-4591. [CrossRef]

151. Ramalingam, N.; Rajiv, S. Curcumin loaded electrospun poly ( 2-hydroxyethyl methacrylate ) p ( HEMA ) nanofibers as Antioxidant and Anticancer agents. J. Adv. Res. Nanosci. Nanotechnol. 2018, 1, 1-9.

152. Feuser, P.E.; Arévalo, J.M.C.; Junior, E.L.; Rossi, G.R.; da Silva Trindade, E.; Rocha, M.E.M.; Jacques, A.V.; Ricci-Júnior, E.; Santos-Silva, M.C.; Sayer, C.; et al. Increased cellular uptake of lauryl gallate loaded in superparamagnetic poly(methyl methacrylate) nanoparticles due to surface modification with folic acid. $J$. Mater. Sci. Mater. Med. 2016, 27. [CrossRef]

153. Ballestri, M.; Caruso, E.; Guerrini, A.; Ferroni, C.; Banfi, S.; Gariboldi, M.; Monti, E.; Sotgiu, G.; Varchi, G. Core-shell poly-methyl methacrylate nanoparticles covalently functionalized with a non-symmetric porphyrin for anticancer photodynamic therapy. J. Photochem. Photobiol. B Biol. 2018, 186, 169-177. [CrossRef]

154. Sobh, R.A.; Nasr, H.E.; Moustafa, A.B.; Mohamed, W.S. Tailoring of anticancer drugs loaded in MWCNT/Poly(MMA-co-HEMA) nanosphere composite by using in situ microemulsion polymerization. J. Pharm. Investig. 2019, 49, 45-55. [CrossRef]

155. Sunoqrot, S.; Abujamous, L. pH-sensitive polymeric nanoparticles of quercetin as a potential colon cancer-targeted nanomedicine. J. Drug Deliv. Sci. Technol. 2019, 52, 670-676. [CrossRef]

156. Osorio-delgado, M.A.; Henao-tamayo, L.J.; Velásquez-cock, J.A.; Isabel, A.; Restrepo-múnera, L.M.; Gañán-rojo, P.F.; Zuluaga-, R.O.; Ortiz-trujillo, I.C.; Castro-herazo, C.I. Biomedical applications of polymeric biomaterials Aplicaciones biomédicas de biomateriales poliméricos. DYNA 2017, 84, 241-252. [CrossRef]

157. Kweon, D.K.; Kang, D.O.O.W. Drug-Release Behavior of Chitosan-g-Poly ( vinyl alcohol ). J. Appl. Polym. Sci. 1999, 74, 458-464. [CrossRef] 
158. Osorio, M.; Velásquez-Cock, J.; Restrepo, L.M.; Zuluaga, R.; Gañán, P.; Rojas, O.J.; Ortiz-Trujillo, I.; Castro, C. Bioactive 3D-Shaped Wound Dressings Synthesized from Bacterial Cellulose: Effect on Cell Adhesion of Polyvinyl Alcohol Integrated In Situ. Int. J. Polym. Sci. 2017, 2017. [CrossRef]

159. Millon, L.E.; Guhados, G.; Wan, W.K. Anisotropic polyvinyl alcohol-bacterial cellulose nanocomposite for biomedical applications. J. Biomed. Mater. Res. Part B Appl. Biomater. 2008, 86, 444-452. [CrossRef] [PubMed]

160. Li, H.; Yan, L.; Tang, E.K.Y.; Zhang, Z.; Chen, W.; Liu, G.; Mo, J. Synthesis of TPGS/Curcumin Nanoparticles by Thin-Film Hydration and Evaluation of Their Anti-Colon Cancer Efficacy In Vitro and In Vivo. Front. Pharmacol. 2019, 10,1-12. [CrossRef]

161. Wen, P.; Hu, T.G.; Wen, Y.; Linhardt, R.J.; Zong, M.H.; Zou, Y.X.; Wu, H. Targeted delivery of phycocyanin for the prevention of colon cancer using electrospun fibers. Food Funct. 2019, 10, 1816-1825. [CrossRef]

162. Golkar, P.; Kalani, S.; Allafchian, A.R.; Mohammadi, H.; Jalali, S.A.H. Fabrication and characterization of electrospun Plantago major seed mucilage/PVA nanofibers. J. Appl. Polym. Sci. 2019, 136, 1-10. [CrossRef]

163. Singh, M.; Tarannum, N. Polyzwitterions. In Engineering of Biomaterials for Drug Delivery Systems Beyond Polyethylene Glycol; Parambath, A.B.T.-E., Ed.; Woodhead Publishing: Cambridge, MA, USA, 2018; pp. 69-101. ISBN 978-0-08-101750-0.

164. Gromadzki, D.; Tzankova, V.; Kondeva, M.; Gorinova, C.; Rychter, P.; Libera, M.; Momekov, G.; Marić, M.; Momekova, D. Amphiphilic core-shell nanoparticles with dimer fatty acid-based aliphatic polyester core and zwitterionic poly(sulfobetaine) shell for controlled delivery of curcumin. Int. J. Polym. Mater. Polym. Biomater. 2017, 66, 915-925. [CrossRef]

165. Viegas, T.X.; Bentley, M.D.; Harris, J.M.; Fang, Z.; Yoon, K.; Dizman, B.; Weimer, R.; Mero, A.; Pasut, G.; Veronese, F.M. Polyoxazoline: Chemistry, properties, and applications in drug delivery. Bioconjug. Chem. 2011, 22, 976-986. [CrossRef]

166. Simon, L.; Vincent, M.; Le Saux, S.; Lapinte, V.; Marcotte, N.; Morille, M.; Dorandeu, C.; Devoisselle, J.M.; Bégu, S. Polyoxazolines based mixed micelles as PEG free formulations for an effective quercetin antioxidant topical delivery. Int. J. Pharm. 2019, 118516. [CrossRef]

167. González-Aramundiz, J.V.; Lozano, M.V.; Sousa-Herves, A.; Fernandez-Megia, E.; Csaba, N. Polypeptides and polyaminoacids in drug delivery. Expert Opin. Drug Deliv. 2012, 9, 183-201. [CrossRef]

168. Patsula, V.; Moskvin, M.; Siow, W.X.; Konefal, R.; Ma, Y.H.; Horák, D. Antioxidant polymer-modified maghemite nanoparticles. J. Magn. Magn. Mater. 2019, 473, 517-526. [CrossRef]

169. Hu, X.; Zheng, W.; Luo, Y.; Ou, X.; Song, L.; Zhang, S.; He, T.; Guo, Z.; Zhu, J.; Shi, H.; et al. Arca subcrenata Polypeptides Inhibit Human Colorectal Cancer HT-29 Cells Growth via Suppression of IGF-1R/Akt/mTOR Signaling and ATP Production. Nutr. Cancer 2019, 0, 1-13. [CrossRef] [PubMed]

170. Lima, A.I.G.; Mota, J.; Monteiro, S.A.V.S.; Ferreira, R.M.S.B. Legume seeds and colorectal cancer revisited: Protease inhibitors reduce MMP-9 activity and colon cancer cell migration. Food Chem. 2016, 197, 30-38. [CrossRef] [PubMed]

171. Chen, Z.; Li, W.; Santhanam, R.K.; Wang, C.; Gao, X.; Chen, Y.; Wang, C.; Xu, L.; Chen, H. Bioactive peptide with antioxidant and anticancer activities from black soybean [Glycine max (L.) Merr.] byproduct: Isolation, identification and molecular docking study. Eur. Food Res. Technol. 2019, 245, 677-689. [CrossRef]

172. González-Montoya, M.; Hernández-Ledesma, B.; Silván, J.M.; Mora-Escobedo, R.; Martínez-Villaluenga, C. Peptides derived from in vitro gastrointestinal digestion of germinated soybean proteins inhibit human colon cancer cells proliferation and inflammation. Food Chem. 2018, 242, 75-82. [CrossRef] [PubMed]

173. Zhang, M.; Mu, T.H. Contribution of different molecular weight fractions to anticancer effect of sweet potato protein hydrolysates by six proteases on HT-29 colon cancer cells. Int. J. Food Sci. Technol. 2018, 53, 525-532. [CrossRef]

174. Luo, T.; Yang, L.; Wu, J.; Zheng, Z.; Li, G.; Wang, X.; Kaplan, D.L. Stabilization of Natural Antioxidants by Silk Biomaterials. ACS Appl. Mater. Interfaces 2016, 8, 13573-13582. [CrossRef]

175. Lerdchai, K.; Kitsongsermthon, J.; Ratanavaraporn, J.; Kanokpanont, S.; Damrongsakkul, S. Thai Silk Fibroin/Gelatin Sponges for the Dual Controlled Release of Curcumin and Docosahexaenoic Acid for Anticancer Treatment. J. Pharm. Sci. 2016, 105, 221-230. [CrossRef]

176. Lozano-Pérez, A.A.; Rivero, H.C.; Pérez Hernández, M.d.C.; Pagán, A.; Montalbán, M.G.; Víllora, G.; Cénis, J.L. Silk fibroin nanoparticles: Efficient vehicles for the natural antioxidant quercetin. Int. J. Pharm. 2017, 518, 11-19. [CrossRef] 
177. Alippilakkotte, S.; Sreejith, L. Pectin mediated synthesis of curcumin loaded poly(lactic acid) nanocapsules for cancer treatment. J. Drug Deliv. Sci. Technol. 2018, 48, 66-74. [CrossRef]

178. Grobelski, B.; Wach, R.A.; Adamus, A.; Olejnik, A.K.; Kowalska-Ludwicka, K.; Kolodziejczyk, M.; Bielecki, S.; Rosiak, J.M.; Pasieka, Z. Biocompatibility of Modified Bionanocellulose and Porous Poly( $\epsilon$-caprolactone) Biomaterials. Int. J. Polym. Mater. Polym. Biomater. 2014, 63, 518-526. [CrossRef]

179. Seyednejad, H.; Gawlitta, D.; Kuiper, R.V.; De Bruin, A.; Van Nostrum, C.F.; Vermonden, T.; Dhert, W.J.A.; Hennink, W.E. In vivo biocompatibility and biodegradation of 3D-printed porous scaffolds based on a hydroxyl-functionalized poly(E-caprolactone). Biomaterials 2012, 33, 4309-4318. [CrossRef] [PubMed]

180. Stoyko, F. Biodegradable Polyesters, 1st ed.; Stoyko, F., Ed.; Wiley: Singapore, 2015; ISBN 9781118837252.

181. Pereira, M.C.; Oliveira, D.A.; Hill, L.E.; Zambiazi, R.C.; Borges, C.D.; Vizzotto, M.; Mertens-Talcott, S.; Talcott, S.; Gomes, C.L. Effect of nanoencapsulation using PLGA on antioxidant and antimicrobial activities of guabiroba fruit phenolic extract. Food Chem. 2018, 240, 396-404. [CrossRef] [PubMed]

182. Kariduraganavar, M.Y.; Kittur, A.A.; Kamble, R.R. Polymer Synthesis and Processing. In Handbook of Polymer Synthesis; Kumbar, S.G., Laurencin, C.T., Deng, M.B.T.-N.S.B.P., Eds.; Elsevier: Oxford, UK, 2014; pp. 1-31. ISBN 978-0-12-396983-5.

183. Sriyanti, I.; Edikresnha, D.; Rahma, A.; Munir, M.M.; Rachmawati, H.; Khairurrijal, K. Correlation between Structures and Antioxidant Activities of Polyvinylpyrrolidone/ Garcinia mangostana L. Extract Composite Nanofiber Mats Prepared Using Electrospinnin. J. Nanomater. 2017, 2017. [CrossRef]

184. Andjani, D.; Sriyanti, I.; Fauzi, A.; Edikresnha, D.; Munir, M.M.; Rachmawati, H. Khairurrijal Rotary Forcespun Polyvinylpyrrolidone (PVP) Fibers as a Mangosteen Pericarp Extracts Carrier. Procedia Eng. 2017, 170, 14-18. [CrossRef]

185. Zahra, F.; Fauzi, A.; Miftahul Munir, M.; Khairurrijal, K. Synthesis and Characterization of Rotary Forcespun Polyvinylpyrrolidone Fibers Loaded by Garlic (Allium sativum) Extract. IOP Conf. Ser. Mater. Sci. Eng. 2019, 515. [CrossRef]

186. Kamaruddin; Sriyanti, I.; Edikresnha, D.; Munir, M.M.; Khairurrijal, K. Electrosprayed polyvinylpyrrolidone (PVP) submicron particles loaded by green tea extracts. IOP Conf. Ser. Mater. Sci. Eng. 2018, 367. [CrossRef]

187. Guamán-Balcázar, M.C.; Montes, A.; Pereyra, C.; Martínez de la Ossa, E. Production of submicron particles of the antioxidants of mango leaves/PVP by supercritical antisolvent extraction process. J. Supercrit. Fluids 2019, 143, 294-304. [CrossRef]

188. Contardi, M.; Heredia-Guerrero, J.A.; Guzman-Puyol, S.; Summa, M.; Benítez, J.J.; Goldoni, L.; Caputo, G.; Cusimano, G.; Picone, P.; Di Carlo, M.; et al. Combining dietary phenolic antioxidants with polyvinylpyrrolidone: Transparent biopolymer films based on: P-coumaric acid for controlled release. J. Mater. Chem. B 2019, 7, 1384-1396. [CrossRef]

189. Thanyacharoen, T.; Chuysinuan, P.; Techasakul, S.; Nooeaid, P.; Ummartyotin, S. Development of a gallic acid-loaded chitosan and polyvinyl alcohol hydrogel composite: Release characteristics and antioxidant activity. Int. J. Biol. Macromol. 2018, 107, 363-370. [CrossRef]

190. Aluani, D.; Tzankova, V.; Kondeva-Burdina, M.; Yordanov, Y.; Nikolova, E.; Odzhakov, F.; Apostolov, A.; Markova, T.; Yoncheva, K. Evaluation of biocompatibility and antioxidant efficiency of chitosan-alginate nanoparticles loaded with quercetin. Int. J. Biol. Macromol. 2017, 103, 771-782. [CrossRef]

191. Rahaiee, S.; Hashemi, M.; Shojaosadati, S.A.; Moini, S.; Razavi, S.H. Nanoparticles based on crocin loaded chitosan-alginate biopolymers: Antioxidant activities, bioavailability and anticancer properties. Int. J. Biol. Macromol. 2017, 99, 401-408. [CrossRef] [PubMed]

192. Huang, X.; Huang, X.; Gong, Y.; Xiao, H.; McClements, D.J.; Hu, K. Enhancement of curcumin water dispersibility and antioxidant activity using core-shell protein-polysaccharide nanoparticles. Food Res. Int. 2016, 87, 1-9. [CrossRef] [PubMed]

193. Wei, Y.; Yu, Z.; Lin, K.; Sun, C.; Dai, L.; Yang, S.; Mao, L.; Yuan, F.; Gao, Y. Fabrication and characterization of resveratrol loaded zein-propylene glycol alginate-rhamnolipid composite nanoparticles: Physicochemical stability, formation mechanism and in vitro digestion. Food Hydrocoll. 2019, 95, 336-348. [CrossRef]

194. Arunkumar, R.; Prashanth, K.V.H.; Manabe, Y.; Hirata, T.; Sugawara, T.; Dharmesh, S.M.; Baskaran, V. Biodegradable poly (lactic-co-glycolic acid)-polyethylene glycol nanocapsules: An efficient carrier for improved solubility, bioavailability, and anticancer property of lutein. J. Pharm. Sci. 2015, 104, 2085-2093. [CrossRef] [PubMed] 
195. Jaiswal, S.; Dutta, P.K.; Kumar, S.; Koh, J.; Pandey, S. Methyl methacrylate modified chitosan: Synthesis, characterization and application in drug and gene delivery. Carbohydr. Polym. 2019, 211, 109-117. [CrossRef]

196. Eatemadi, A.; Daraee, H.; Aiyelabegan, H.T.; Negahdari, B.; Rajeian, B.; Zarghami, N. Synthesis and Characterization of Chrysin-loaded PCL-PEG-PCL nanoparticle and its effect on breast cancer cell line. Biomed. Pharmacother. 2016, 84, 1915-1922. [CrossRef]

197. Wu, C.S.; Liao, H.T. Interface design and reinforced features of arrowroot (Maranta arundinacea) starch/polyester-based membranes: Preparation, antioxidant activity, and cytocompatibility. Mater. Sci. Eng. C 2016, 70, 54-61. [CrossRef]

198. Teiten, M.H.; Dicato, M.; Diederich, M. Hybrid curcumin compounds: A new strategy for cancer treatment. Molecules 2014, 19, 20839-20863. [CrossRef]

199. Abdel Latif, Y.; El-Bana, M.; Hussein, J.; El-Khayat, Z.; Farrag, A.R. Effects of resveratrol in combination with 5-fluorouracil on $\mathrm{N}$-methylnitrosourea-induced colon cancer in rats. Comp. Clin. Path. 2019. [CrossRef]

200. Carrillo, E.; Navarro, S.A.; Ramírez, A.; García, M.Á.; Griñán-Lisón, C.; Perán, M.; Marchal, J.A. 5-fluorouracil derivatives: A patent review (2012-2014). Expert Opin. Ther. Pat. 2015, 25, 1131-1144. [CrossRef]

201. Han, R.; Sun, Y.; Kang, C.; Sun, H.; Wei, W. Amphiphilic dendritic nanomicelle-mediated co-delivery of 5-fluorouracil and doxorubicin for enhanced therapeutic efficacy. J. Drug Target. 2017, 25, 140-148. [CrossRef] [PubMed]

202. Moodley, T.; Singh, M. Polymeric mesoporous silica nanoparticles for enhanced delivery of 5-fluorouracil in vitro. Pharmaceutics 2019, 11, 288. [CrossRef] [PubMed]

203. Wang, Y.; Li, P.; Chen, L.; Gao, W.; Zeng, F.; Kong, L.X. Targeted delivery of 5-fluorouracil to HT-29 cells using high efficient folic acid-conjugated nanoparticles. Drug Deliv. 2015, 22, 191-198. [CrossRef]

204. Anirudhan, T.S.; Christa, J. Binusreejayan $\mathrm{pH}$ and magnetic field sensitive folic acid conjugated protein-polyelectrolyte complex for the controlled and targeted delivery of 5-fluorouracil. J. Ind. Eng. Chem. 2018, 57, 199-207. [CrossRef]

205. Hariharan, M.S.; Sivaraj, R.; Ponsubha, S.; Jagadeesh, R.; Enoch, I.V.M.V. 5-Fluorouracil-loaded $\beta$-cyclodextrin-carrying polymeric poly(methylmethacrylate)-coated samarium ferrite nanoparticles and their anticancer activity. J. Mater. Sci. 2019, 54, 4942-4951. [CrossRef]

206. Roth Stefaniak, K.; Epley, C.C.; Novak, J.J.; McAndrew, M.L.; Cornell, H.D.; Zhu, J.; McDaniel, D.K.; Davis, J.L.; Allen, I.C.; Morris, A.J.; et al. Photo-triggered release of 5-fluorouracil from a MOF drug delivery vehicle. Chem. Commun. 2018, 54, 7617-7620. [CrossRef] [PubMed]

207. Hadjianfar, M.; Semnani, D.; Varshosaz, J. Polycaprolactone/chitosan blend nanofibers loaded by 5-fluorouracil: An approach to anticancer drug delivery system. Polym. Adv. Technol. 2018, 29, 2972-2981. [CrossRef]

208. Gioumouxouzis, C.I.; Chatzitaki, A.-T.; Karavasili, C.; Katsamenis, O.L.; Tzetzis, D.; Mystiridou, E.; Bouropoulos, N.; Fatouros, D.G. Controlled Release of 5-Fluorouracil from Alginate Beads Encapsulated in 3D Printed pH-Responsive Solid Dosage Forms. AAPS PharmSciTech. 2018, 19, 3362-3375. [CrossRef]

209. Pal, P.; Pandey, J.P.; Sen, G. Sesbania gum based hydrogel as platform for sustained drug delivery: An 'in vitro' study of 5-Fu release. Int. J. Biol. Macromol. 2018, 113, 1116-1124. [CrossRef]

210. Ma, Z.; Ma, R.; Wang, X.; Gao, J.; Zheng, Y.; Sun, Z. Enzyme and PH responsive 5-flurouracil (5-FU)loaded hydrogels based on olsalazine derivatives for colon-specific drug delivery. Eur. Polym. J. 2019, 118, 64-70. [CrossRef]

211. Sun, X.; Liu, C.; Omer, A.M.; Lu, W.; Zhang, S.; Jiang, X.; Wu, H.; Yu, D.; Ouyang, X. kun pH-sensitive $\mathrm{ZnO} /$ carboxymethyl cellulose/chitosan bio-nanocomposite beads for colon-specific release of 5-fluorouracil. Int. J. Biol. Macromol. 2019, 128, 468-479. [CrossRef] [PubMed]

212. Cuadra, I.A.; Zahran, F.; Martín, D.; Cabañas, A.; Pando, C. Preparation of 5-fluorouracil microparticles and 5-fluorouracil/poly(L-lactide) composites by a supercritical CO2 antisolvent process. J. Supercrit. Fluids 2019, 143, 64-71. [CrossRef]

213. Khan, S.; Anwar, N. Highly Porous pH-Responsive Carboxymethyl Chitosan- Grafted -Poly (Acrylic Acid) Based Smart Hydrogels for 5-Fluorouracil Controlled Delivery and Colon Targeting. Int. J. Polym. Sci. 2019, 2019. [CrossRef]

214. Yan, J.K.; Qiu, W.Y.; Wang, Y.Y.; Wu, L.X.; Cheung, P.C.K. Formation and characterization of polyelectrolyte complex synthesized by chitosan and carboxylic curdlan for 5-fluorouracil delivery. Int. J. Biol. Macromol. 2018, 107, 397-405. [CrossRef] 
215. Wu, X.; He, C.; Wu, Y.; Chen, X. Synergistic therapeutic effects of Schiff's base cross-linked injectable hydrogels for local co-delivery of metformin and 5-fluorouracil in a mouse colon carcinoma model. Biomaterials 2016, 75, 148-162. [CrossRef]

216. Wang, Y.; Bai, F.; Luo, Q.; Wu, M.; Song, G.; Zhang, H.; Cao, J.; Wang, Y. Lycium barbarum polysaccharides grafted with doxorubicin: An efficient $\mathrm{pH}$-responsive anticancer drug delivery system. Int. J. Biol. Macromol. 2019, 121, 964-970. [CrossRef]

217. Dhanavel, S.; Revathy, T.A.; Sivaranjani, T.; Sivakumar, K.; Palani, P.; Narayanan, V.; Stephen, A. 5-Fluorouracil and curcumin co-encapsulated chitosan/reduced graphene oxide nanocomposites against human colon cancer cell lines. Polym. Bull. 2019. [CrossRef]

C 2020 by the authors. Licensee MDPI, Basel, Switzerland. This article is an open access article distributed under the terms and conditions of the Creative Commons Attribution (CC BY) license (http://creativecommons.org/licenses/by/4.0/). 